NBER WORKING PAPER SERIES

\title{
POLITICS AND EFFICIENCY OF SEPARATING CAPITAL AND ORDINARY GOVERNMENT BUDGETS
}

\author{
Marco Bassetto \\ Thomas J. Sargent \\ Working Paper 11030 \\ http://www.nber.org/papers/w11030
NATIONAL BUREAU OF ECONOMIC RESEARCH
1050 Massachusetts Avenue
Cambridge, MA 02138
January 2005

We benefited from comments by Manuel Amador, V.V. Chari, Robert Lucas, Ellen McGrattan, Edward C. Prescott, Robert Shimer, Nancy Stokey, Judy Temple, Francois Velde, and Ivan Werning. Florin Bidian and Vadym Lepetyuk provided excellent research assistance. Financial support from NSF is gratefully acknowledged. The views expressed herein are those of the authors and not necessarily those of the Federal Reserve Bank of Minneapolis, the Federal Reserve System, or NSF. The views expressed herein are those of the author(s) and do not necessarily reflect the views of the National Bureau of Economic Research.

(C) 2005 by Marco Bassetto and Thomas J. Sargent. All rights reserved. Short sections of text, not to exceed two paragraphs, may be quoted without explicit permission provided that full credit, including $\odot$ notice, is given to the source. 
Politics and Efficiency of Separating Capital and Ordinary Government Budgets Marco Bassetto and Thomas J. Sargent

NBER Working Paper No. 11030

January 2005, Revised May 2006

JEL No. E6, H6, H7

\section{ABSTRACT}

We analyze the democratic politics of a rule that separates capital and ordinary account budgets and allows the government to issue debt to finance capital items only. Many national governments followed this rule in the 18th and 19th centuries and most U.S. states do today. This simple 1800s financing rule sometimes provides excellent incentives for majorities to choose an efficient mix of public goods in an economy with a growing population of overlapping generations of long-lived but mortal agents. In a special limiting case with demographics that make Ricardian equivalence prevail, the 1800 s rule does nothing to promote efficiency. But when the demographics imply even a moderate departure from Ricardian equivalence, imposing the rule substantially improves the efficiency of democratically chosen allocations. We calibrate some examples to U.S. demographic data. We speculate why in the twentieth century most national governments abandoned the 1800 s rule while U.S. state governments have retained it.

Marco Bassetto

Department of Economics

University of Minnesota

$2711^{\text {th }}$ Ave S.

Minneapolis, MN 55455

bassetto@econ.umn.edu

Thomas J. Sargent

Department of Economics

New York University

269 Mercer Street

New York, NY 10003

and NBER

ts43@nyu.edu 


\section{The 1800s rule and its purposes}

The gold standard, which the 18th century bequeathed to the 19th, but which the 20th century forgot, prescribed that national governments should promise to convert their debts into gold, either on demand, for currency, or at a specified future date, for bonds. A government's budget constraint dictated that a fiscal rule accompany the gold standard, one that would force a national government to balance its budget in the present value sense while abstaining from an inflation $\operatorname{tax}$.

The 19th century practice of keeping separate capital and ordinary government budgets was one among many possible formulas that could achieve the present value budget balance needed to support the gold standard. This particular formula forbad deficits on the ordinary account but allowed capital account deficits that were balanced by prospective capital account surpluses sufficient to service the newly issued debt. A common practice was to dedicate particular revenue sources to service debt that had been issued to finance a particular capital project. ${ }^{1}$

We call this 'the 1800s fiscal rule' because that seems to have been its golden age. The 19th century data for Britain and the U.S. states conform to this fiscal rule, provided that we allocate war expenditures to the capital account. While most national governments have now abandoned this practice, the rule survives in the constitutions of most U.S. states. ${ }^{2}$ This rule is one of the main factors that forced U.S. states to retrench in the last few years, while its absence allowed the federal government to expand its spending and cut its tax rates in the face of adverse shocks to tax revenues like those affecting the states.

Because of how the Maastricht treaty limits a country's ability to run deficits, recent discussions in the European Union have focused on good ways of restricting government indebtedness.

\footnotetext{
${ }^{1}$ Another common rule in the 19th century imposed severe limits on the quantities of government debt that a central bank could own. Many central banks operated under a rule that at the margin allowed them to conduct open market operations in short term securities issued only by private citizens. While this restriction might be undone by traders executing the sorts of strategies that underly the Modigliani-Miller theorem, it embraces the spirit of the 1800s rule, which was to limit the national treasury's access to easy sources of credit.

${ }^{2}$ Evidence that these rules affect government behavior is presented in Bohn and Inman [4], Poterba [20, 21, 22] and Poterba and Rueben [23].
} 
Proposals to distinguish between ordinary and capital-account expenses have been debated and are serious options, should the Maastricht criteria be changed in the near future. ${ }^{3}$

While the 1800s rule rendered fiscal policy consistent with a national commitment to the gold standard, many other rules would have too. Any fiscal rule that achieved present value budget balance without seigniorage revenues could also have sustained the gold standard, including many rules that would have tolerated temporary deficits to pay for recurrent government expenses. With its careful distinction between capital and ordinary deficits, the 1800s rule served purposes beyond its role in supplementing the gold standard.

This paper highlights one of those additional purposes of the 1800s rule in an economy with successive generations of voters and a democratic government. We focus on how the rule shapes the incentives that voters confront when they choose among alternative levels of nondurable and durable public goods. A constitutional rule that prohibits government borrowing for ordinary expenses affects voters' incentives to consume public goods.

The 1800s rule is simple. It requires information only about the output of the public sector and its division between durable and nondurable public goods. It does not require detailed knowledge about productivity shocks or households' preferences for public goods. ${ }^{4}$

We study a budget rule as a "constitutional contract" constraining overlapping generations of voting households who like private consumption and durable and nondurable public goods. The contract sets rules for intergenerational transfers, the provision of public goods, and the issuing of debt by a centralized institution called "government". The contract is established before the shocks impinging on the economy are realized and consists of two fixed parameters, an $\alpha$ that specifies a debt redemption rate and an $x$ that specifies the fraction of investment to be financed by debt. Particular settings of these parameters separate ordinary and capital government budgets. Within the institutional framework of the contract, a political-economic

\footnotetext{
${ }^{3}$ See e.g. Buiter [6].

${ }^{4}$ We study an environment in which it would be difficult for different generations to enforce constitutional contracts based explicitly on the history of shocks. Therefore, we require budget rules to depend only on the history of capital accumulation and the provision of public goods. See Hansen, Roberds, and Sargent [13] for an analysis of how difficult it is to verify present value budget balance from time series observations on government expenditures and tax collections.
} 
equilibrium is a competitive equilibrium in which durable and nondurable public goods are chosen by democratic voting in each period. In making political choices, households take into account how the current choice affects the outcomes of future elections. We study how the $(\alpha, x)$ pair influences the efficiency of outcomes in the political equilibrium. Outcomes depend on details of the demographic structure in ways that we think may shed light on why the 20th century saw the 1800s rule disappear among many national governments but not at the state level in the U.S.

Section 2 mentions evidence about the 1800s rule. Section 3 presents a benchmark economy in which the 1800's rule supports an efficient allocation as a political-economic equilibrium. This section shows how the 1800's rule is attractive because it provides incentives for each generation to supply the efficient amount of public goods, independently of the history of shocks. Section 4 calibrates the benchmark economy to assess the optimal amount of debt financing, as well as the costs of deviating from it, and section 5 concludes. The robustness of the results to alternative specifications of preferences is studied in appendix C.

\section{The advocates and history of the 1800s rule}

Although John Maynard Keynes disliked the gold standard, he advocated the 1800s fiscal rule that seemed to have accompanied the gold standard and, at least the national level, to have disappeared with it. Robert Skidelsky [31] discusses Keynes's preference for separating ordinary and capital budgets, for always balancing the ordinary budget, and for confining countercyclical deficits to the capital account. Keynes proposed timing capital account deficits to fight unemployment. ${ }^{5}$

\footnotetext{
${ }^{5}$ Keynes' advocacy of a rule that separated capital and ordinary budgets may have reflected no more than that he saw no good reason to abandon what he had observed was best practice among modern states in the 19th century. On other issues, Keynes's policy advice sometimes amounted to recommending what he saw as best late 19th century practice. For example, to reform the Indian currency Keynes [15] advocated that India adopt the gold exchange standard into which Britain and other advanced countries had evolved. However, in a personal communication to us (letter dated 2003-11-16), Lord Skidelsky suggests that it was only the substantial expansion of public investment projects in 20th century Britain that started Keynes to think about the issue. Skidelsky knows of no direct documents that would support our "best 19th century practice" conjecture about
} 
Writing about the 'dual monarchy' of Austria and Hungary before World War I, Pasvolsky [17] states that

Each had an ordinary and an extraordinary budget, the expenditures under the latter being mainly for railroad construction and military needs.

Paul Studensky [32] and E. Cary Brown [5] painted a picture of the United States in which for much of the 1800s, state governments explicitly adhered to the 1800s rule, while the federal government adhered to it for military expenditures. Brown states:

Up to World War II, the expected and well accepted policy of the federal government was to repay outstanding debt in a more or less systematic way, even when accomplished, as it often was, by substantial subsidies to creditors through price deflation. (p. 229)

Until the time of the Great Depression of the 1930s, the major reason for borrowing by the United States government was the preparation for or waging of war. Until then a relatively narrow stance had been maintained with respect to the kinds of programs considered appropriate to undertake. State governments, on the other hand, had assumed a broader role in the 19th century in financing transportation and other developmental projects. Local governments grew explosively after the Civil War to provide needed urban utilities and infrastructures. (p. 229)

Speaking of the prevailing theory about financing state and local expenditures on "lasting improvements" Paul Studensky wrote:

It was contended also that such expenditures [permanent improvements] would benefit future generations as much as the present generation; that future generations should consequently be made to contribute to their defrayment; and that this could be accomplished only if the expenditures were financed by means payable in the future. ${ }^{6}$ (p. 15$)$

the source of Keynes's preference for the 1800s rule.

${ }^{6}$ Later in his book, Studensky criticized this rule and proposed improvements. 
Consistent with this theory, a policy of borrowing was developed along the following lines: borrowing was resorted to for all expenditures for permanent improvements; each project was considered separately and a separate loan incurred for it; the bonds were earmarked so that the proceeds could be used only for the project for which they were authorized; ... (p. 16).

Later, Studensky explained how the federal government mostly avoided borrowing to finance its "lasting improvements":

... how does it happen that the federal government has managed to finance its internal improvements with little if any borrowing ...? (p. 84) The explanation is found in the peculiar nature of the national expenditure and revenue systems. Those for war have been practically the only extraordinary expenditures. All other expenditures have been considered ordinary. The government was expected to borrow in times of war and to pay off its debt - certainly not to borrow in addition - in times of peace. The revenues consisted exclusively, until recent times, of customs duties and a few indirect taxes. The revenues from these sources during periods of prosperity not only were ample for all purposes of government, and took care of all the necessary permanent improvements without burdening the people, but were even yielding large annual surpluses. There was no excuse for borrowing under these circumstances. The federal government has very seldom ventured on any very large programs of improvement, other than those connected with its military and naval establishment, which could not be taken care of by its ordinary revenues. In the few instances in which it has ventured on such programs, it had to resort to loans. It had to borrow also in some cases to place its monetary system on a sound basis." (p. 85)

Writing in 1930, Studensky foresaw irrepressible pressures to depart from the 1800s rule, and Brown's [5] account confirms the breakdown. 


\section{The Benchmark Economy}

In this section, we consider an environment in which a mechanism resembling the 1800 s rule implements a Pareto-optimal allocation. A key feature is the quasilinearity of household preferences, which, by implying risk neutrality, eliminates any loss from the lack of intergenerational insurance.

\subsection{Preferences and technology}

We consider an economy populated by a continuum of households in overlapping generations. Once born, each household faces a probability $1-\theta_{s}$ of death in its $s$-th period of life, conditional on having survived until then. ${ }^{7}$ Population grows at a constant rate $n$.

Households consume a private good in each period of their lives. They also enjoy the services of two public goods. One is nondurable and another is durable and called public capital. Households supply labor services, at some utility cost. We interpret public capital in either of two ways. First, it includes publicly-funded infrastructure (such as bridges, canals, railroads, sewers, etc.); second, it can also include "national security," a public good that is difficult to measure, but is revealed to be important by the resources countries devote to military purposes.

A household born in period $t$ has preferences ordered by

$$
E_{t} \sum_{s=t}^{N+t} \beta^{s-t}\left(\prod_{j=0}^{s-t-1} \theta_{j}\right)\left[c_{s-t, s}+v\left(G_{s}, \Gamma_{s}\right)-\phi\left(l_{s-t, s}\right)\right]
$$

where $N+1$ periods is the longest a household can live, ${ }^{8} c_{s-t, s}$ and $l_{s-t, s}$ are consumption of the private good and the labor supply in period $s$ by a household of age $s-t$ (born in period $t$ ), $G_{s}$ is the amount of nondurable public good per capita in period $s$, and $\Gamma_{s}$ is the stock of the durable public good per capita in period $s$. We assume that $v$ is strictly concave, $\phi$ is strictly

\footnotetext{
${ }^{7}$ We assume that a fraction $1-\theta_{s}$ of households of age $s$ die every period. In this section, we also assume that the age structure of the population at time 0 coincides with the demographic steady state associated with the survival probabilities and population growth. We relax this assumption in the calibration.

${ }^{8}$ We allow for the possibility that $N=\infty$. Here, and throughout the paper, we adopt the notational convention $\left(\prod_{j=0}^{-1} \theta_{j}\right) \equiv 1$.
} 
convex, and both $v$ and $\phi$ are twice continuously differentiable and satisfy Inada conditions. We also assume $\beta(1+n)<1$. The expected value is taken with respect to the uncertainty adapted to the aggregate state; the presence of $\theta_{j}$ terms reflects idiosyncratic uncertainty over the life span, which is assumed to be independent of aggregate shocks.

All goods are produced with one intermediate good. Each firm can turn $K$ units of capital and $L$ units of labor into $A_{t} F(K, L)$ units of the intermediate good. We assume $F$ to be increasing, concave, continuously differentiable, linearly homogeneous and to satisfy Inada conditions; $A_{t}$ is a stochastic process, whose domain is nonnegative, bounded, and bounded away from 0 .

Firms can turn each unit of the intermediate good into one unit of the private consumption good, $1 / q_{t}^{k}$ units of private capital, $1 / q_{t}^{G}$ units of the nondurable public good, and $1 / q_{t}^{\Gamma}$ units of public capital; $q_{t}^{k}, q_{t}^{G}$ and $q_{t}^{\Gamma}$ are stochastic processes that are nonnegative, bounded, and bounded away from 0 .

Private capital depreciates at a rate $\delta^{k}$, and public capital depreciates at a rate $\delta_{t}^{\Gamma}$, where the latter is stochastic, with a domain in $[0,1) .{ }^{9}$ We define $s_{t} \equiv\left(A_{t}, q_{t}^{k}, q_{t}^{G}, q_{t}^{\Gamma}, \delta_{t}^{\Gamma}\right)$ to be the shock that hits the economy at time $t$. All variables with a subscript $t$ are assumed to be adapted to $s_{t}$.

The economy-wide resource constraints are

$$
\begin{gathered}
C_{t}+q_{t}^{k} i_{t}+q_{t}^{G} G_{t}+q_{t}^{\Gamma} \gamma_{t} \leq A_{t} F\left(\frac{K_{t-1}}{1+n}, L_{t}\right) \\
K_{t} \leq\left(1-\delta^{k}\right) \frac{K_{t-1}}{1+n}+i_{t} \\
\Gamma_{t} \leq\left(1-\delta_{t}^{\Gamma}\right) \frac{\Gamma_{t-1}}{1+n}+\gamma_{t}
\end{gathered}
$$

where $i_{t}$ is investment in private capital per capita, $\gamma_{t}$ is investment in public capital per capita, $K_{t}$ is the capital stock per capita at the end of period $t$ (to be used for production in period

\footnotetext{
${ }^{9}$ Stochastic depreciation of public capital is introduced mainly to justify wars: we view them as being the government response to a bad shock to the stock of "national security."
} 
$t+1$ ), and $C_{t}$ and $L_{t}$ are consumption and the labor supply per capita:

$$
\begin{aligned}
L_{t} & \equiv \sum_{s=0}^{N} \lambda_{s} l_{s, t} \\
C_{t} & \equiv \sum_{s=0}^{N} \lambda_{s} c_{s, t}
\end{aligned}
$$

Also,

$$
\lambda_{s} \equiv \frac{(1+n)^{-s} \prod_{j=0}^{s-1} \theta_{j}}{\sum_{t=0}^{N}(1+n)^{-t} \prod_{j=0}^{t-1} \theta_{j}}
$$

is the fraction of households of age $s$. The initial values of $K_{-1}$ and $\Gamma_{-1}$ are exogenously given.

\subsection{Pareto-optimal allocations}

Either we assume that private consumption can be negative or, more realistically, we will restrict our analysis to a range of parameters and utility entitlements for the generations such that private consumption is positive.

We define a stochastic process $\left\{\left\{c_{s, t}, l_{s, t}\right\}_{s=0}^{N}, i_{t}, \gamma_{t}, G_{t}, K_{t}, \Gamma_{t}\right\}_{t=0}^{\infty}$ to be a feasible (real) allocation if it satisfies equations (2), (3), and (4) and is bounded. ${ }^{10}$ We define a feasible allocation to be efficient or ex ante Pareto optimal if there is no other feasible allocation that delivers a weakly higher expected utility to each generation and a strictly higher utility to at least one generation. We thus measure from the perspective of households that know to which generation they belong but not the realizations of shocks. ${ }^{11}$

The quasilinearity of utility in consumption makes characterizing efficient allocations particularly simple. In each period $t$, taking 1 unit of consumption per capita from each surviving household born in period $t-j$ allows a planner to award a consumption increase of $\lambda_{j} / \lambda_{s}$ to each

\footnotetext{
${ }^{10}$ The term "real" is introduced to distinguish this allocation from the asset allocation, which we will introduce later. Wherever not specified, by allocation we mean real allocation. The assumption of boundedness could be relaxed, but bounded sequences are a particularly simple commodity space to work with. Notice that all infinite sums that we introduce will be well defined in this commodity space. Technological growth could be accommodated by suitably rescaling variables and introducing a shifter in preferences to ensure stationarity.

${ }^{11}$ In this setup with quasilinear utility, the difference between ex ante and ex post Pareto optimality is not too important.
} 
surviving household born in period $t-s$. The expected utility cost for the former generation is $\beta^{j} \prod_{m=0}^{j-1} \theta_{m}$, and the expected utility gain for the latter is $\frac{\beta^{s} \prod_{m=0}^{j-1} \theta_{m}}{(1+n)^{j-s}}{ }^{12}$ The slope of the Pareto frontier is uniquely pinned down as the ratio, i.e., $[\beta(1+n)]^{j-s}$. Movements along the frontier are achieved simply by redistributing consumption, without affecting other variables. The difference between this situation and a standard Pareto problem, with strictly concave utility, is illustrated in figure 1; in the standard problem, the slope of the utility depends on the allocation, and the frontier is recovered by varying the Pareto weights assigned to each group in the Pareto problem; with quasilinear preferences, a fixed Pareto weight corresponds to all utility pairs, so that the frontier is not to be traced out by varying the Pareto weight.
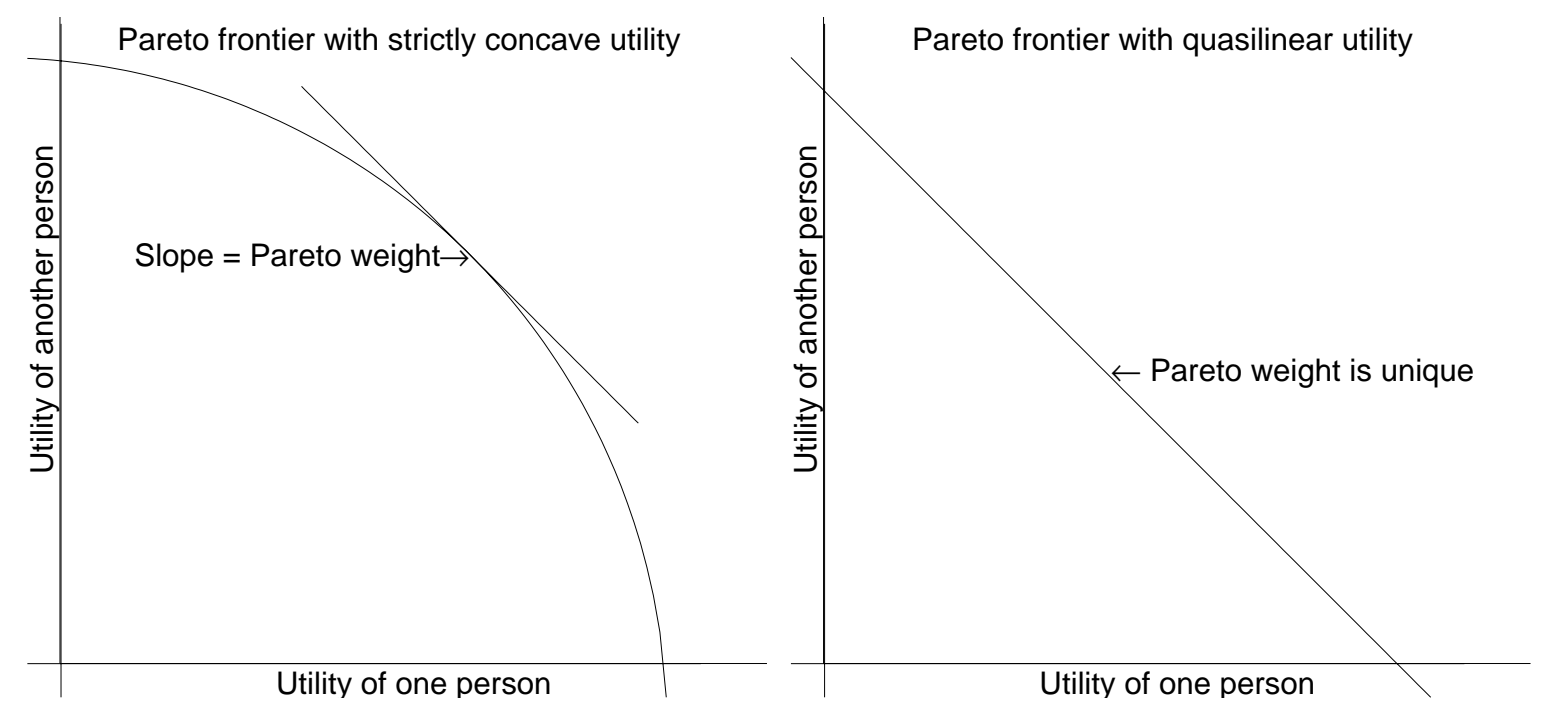

Figure 1: Pareto problem and the shape of the frontier

We consider only those allocations in which all households belonging to the same cohort are treated symmetrically. Among these, an efficient allocation solves the following

\section{Pareto problem:}

$$
\max _{\left\{C_{t}, G_{t}, \Gamma_{t}, i_{t}, \gamma_{t},\left\{l_{s, t}\right\}_{s=0}^{N}, k_{t}\right\}_{t=0}^{\infty}} E \sum_{t=0}^{\infty}[\beta(1+n)]^{t}\left\{C_{t}+v\left(G_{t}, \Gamma_{t}\right)-\sum_{s=0}^{N} \lambda_{s} \phi\left(l_{s, t}\right)\right\}
$$

\footnotetext{
${ }^{12}$ If $t-j<0$, we measure utility from time 0 , so the expected utility cost is $\beta^{t} \prod_{m=j-t}^{j-1} \theta_{m}$. Likewise, if $t-s<0$, the expected utility gain is $\frac{\beta^{t} \prod_{m=0}^{j-1} \theta_{m}}{(1+n)^{j-s} \prod_{m=0}^{s-t-1} \theta_{m}}$.
} 
subject to (2), (3) and (4).

The first-order conditions for this problem yield

$$
\begin{gathered}
v_{G}\left(G_{t}, \Gamma_{t}\right)=q_{t}^{G}, \quad t=0, \ldots \\
v_{\Gamma}\left(G_{t}, \Gamma_{t}\right)=q_{t}^{\Gamma}-\beta E_{t}\left(1-\delta_{t+1}^{\Gamma}\right) q_{t+1}^{\Gamma}, \quad t=0, \ldots \\
\phi^{\prime}\left(l_{s, t}\right)=A_{t} F_{l}\left(\frac{K_{t-1}}{1+n}, L_{t}\right) \quad t=0, \ldots, \quad s=0, \ldots, N \\
E_{t}\left[A_{t+1} F_{k}\left(\frac{K_{t}}{1+n}, L_{t+1}\right)\right]=\frac{q_{t}^{k}}{\beta}-\left(1-\delta^{k}\right) E_{t} q_{t+1}^{k} \quad t=0, \ldots
\end{gathered}
$$

Equation (9) implies that all households supply the same amount of labor: $l_{s, t}=L_{t}, s=0, \ldots, N$. Equation (9) evaluated at time $t+1$ can then be uniquely solved for $L_{t+1}$ and substituted into (10). The assumptions about $F$ and $\phi^{\prime}$ guarantee that the left-hand side is a well-defined, strictly decreasing function of $K_{t}$, and that a (unique) solution exists. From that equation, we thus obtain that all Pareto optima must share the same level of private capital and hence the same labor supply. Equations (7) and (8) imply that $G_{t}$ and $\Gamma_{t}$ are uniquely determined as well. All of these variables are independent of the initial level of public capital, $\Gamma_{-1}$. Investment can then be deduced from (3) and (4), and consumption per capita (but not its allocation across different cohorts) from (2).

\subsection{Implementing Pareto Optima}

We will show that any Pareto-optimal allocation can be attained through the following institutional framework. In the beginning, households establish "government", an institution empowered to levy taxes, purchase public goods, and provide transfers. The constitution specifies that public goods are chosen each period by majority vote. The constitution names two parameters $(\alpha, x)$ that restrict debt repayment and government borrowing; a fraction $\alpha$ of government issued consols is to be redeemed each period and a fraction $x$ of public investment is paid for with debt. The economy unfolds as follows:

(i) In period $t$, the government purchases $G_{t}$ and $\gamma_{t}$ from competitive firms. The amount is chosen by majority voting, subject to financing restrictions to be described below. 
(ii) Taxes are lump sum and levied equally on each household alive.

(iii) Each unit of nondurable spending $G_{t}$ must be financed from taxes levied in period $t$.

(iv) For each unit of public investment $\gamma_{t}$, a fraction $x$ is paid for by issuing new consols. ${ }^{13}$

(v) In each period, the government raises enough taxes to pay interest on outstanding consols and to repurchase a fraction $\alpha>0$ of them.

(vi) To achieve the appropriate distribution of welfare, the government is committed ex ante to an appropriate bounded sequence of unconditional transfers $\left\{T_{t}\right\}_{t=-N}^{\infty}$ to the cohort born in period $t$. The transfer is paid out in each period that a household is alive and is financed by current taxes. Different assumptions about the schedule for debt repayment imply that different sequences of transfers are needed to achieve a given utility assignment.

(vii) Households and firms trade goods and factors of production in competitive markets.

Features (i), (iii), and (iv) capture the 1800's rule. The "constitution" does not specify the level of provision of the public goods but restricts how to pay for them. The financing restrictions provide incentives for voters to choose efficient amounts of public goods.

An attractive feature of this institutional setup is its simplicity. Future generations require very little information about past behavior, making it easier to enforce such a rule (e.g., by threatening to repudiate government debt); by contrast, more complicated mechanisms would require future generations to acquire more information about their predecessors' decisions to establish whether they had conformed to the rule. Therefore, it could take longer for a more complicated rule to become understood and consented to. ${ }^{14} \mathrm{~A}$ benchmark assumption about the

\footnotetext{
${ }^{13}$ Different debt maturities and repayment schedules could be considered, provided the amounts of bonds and lump-sum transfers are adjusted appropriately. In what follows, we will assume that the government issues exactly $x$. When median $\left(\theta_{s}\right)<1+n$, as we will generally assume, the conditions that ensure that it is desirable to set $x$ to a positive number also ensure that all the people alive will benefit from issuing debt, so that issuing the full amount $x$ would be chosen even if the constitution prescribed a limit on debt issuance only, rather than a level.

${ }^{14}$ We don't model a process through which a government rule of conduct is established, but that could be a fascinating exercise. For sure, for U.S. state governments, the 1800s rule did not emerge in a vacuum. Wallis [34]
} 
transfers in part (vi) is that none takes place; this amounts to choosing a specific point on the Pareto frontier.

\subsection{Analysis}

We first describe the households' optimization problem, and then define an equilibrium. We assume that households can trade one-period debt, in addition to physical capital and government consols. ${ }^{15}$

A tax-debt policy is a bounded sequence $\left\{\tau_{t}, B_{t}\right\}_{t=0}^{\infty}$, where $\tau_{t}$ are lump-sum taxes per capita in period $t$ and $B_{t}$ is the amount of government-issued consols per capita at the end of period $t$. We set the coupon payment on each consol to 1 . A price system is a sequence $\left\{w_{t}, r_{t}, p_{t}, \pi_{t}\right\}_{t=0}^{\infty}$, where $w_{t}$ is the wage rate in period $t, r_{t}$ is the rental rate of capital, $p_{t}$ is the price of a consol, exclusive of the time- $t$ coupon payment, and $\pi_{t}$ is the price of a 1-period pure discount bond. An asset allocation is a sequence $\left\{\left\{k_{s, t}, b_{s, t}, a_{s, t}\right\}_{s=0}^{N-1}\right\}_{t=0}^{\infty}$ consisting of the capital, the government consols, and one-period bonds held by a household of the cohort born in $t-s$ at the end of period $t$.

A household born in period $s \geq 0$ solves the following problem, taking as given the price describes how twelve U.S. states adopted new state constitutions during the 1840s, most formalizing a version of the 1800s rule. Wallis describes those constitutional reforms as responses to problems that befell earlier attempts by the state governments to finance internal improvements, some with "taxless finance", others with "benefit taxation". See Wallis and Weingast [35] for a convincing account of the consequences for the political processes for choosing public investments ('internal improvements'), whether by the federal government or by the states, of the clause in the U.S. constitution that forbad the federal government to impose direct taxes, except in proportion to states' populations. Wallis and Weingast describe how that clause made it virtually impossible to form winning coalitions in the U.S. congress for large local public works. They go on to describe how, by effectively turning public works over to the state legislatures, that clause worked to create a viable federalism that kept states in the union.

${ }^{15}$ One-period debt is considered mainly to rule out bubbles in the price of consols. When $N=\infty$, its presence is sufficient to rule out bubbles, as long as short-selling constraints limit households to portfolio positions that are essentially bounded from below. When $N$ is finite, it is necessary to assume that households can set up an infinitely-lived intermediary that is subject to similar short-selling constraints. Huang and Werner [14] provide a complete treatment of this issue. 
system and the tax policy:

$$
\max E_{s} \sum_{t=s}^{s+N} \beta^{t-s}\left(\prod_{j=0}^{t-s-1} \theta_{j}\right)\left[c_{t-s, t}-\phi\left(l_{t-s, t}\right)\right]
$$

subject to the flow budget constraint

$$
\begin{aligned}
& c_{t-s, t}+q_{t}^{k} k_{t-s, t}+p_{t} b_{t-s, t}+\pi_{t} a_{t-s, t} \leq w_{t} l_{t-s, t}-\tau_{t}+T_{s}+ \\
& \frac{\left[r_{t}+\left(1-\delta^{k}\right) q_{t}^{k}\right]}{\theta_{t-s-1}} k_{t-s-1, t-1}+\frac{\left(p_{t}+1\right)}{\theta_{t-s-1}} b_{t-s-1, t-1}+\frac{a_{t-s-1, t-1}}{\theta_{t-s-1}} \quad t=s, \ldots, s+N
\end{aligned}
$$

This budget constraint assumes that households participate in a collective insurance agreement, whereby the assets of people who die are redistributed to the survivors in proportion to their holdings. The existence of this insurance agreement is necessary for the competitive equilibrium to be Pareto-optimal, and it is optimal for households to participate. We assume that households start with no wealth, so $k_{-1, s-1}=b_{-1, s-1}=a_{-1, s-1}=0 .{ }^{16}$

To prevent Ponzi schemes, it is necessary to impose a borrowing limit on households. If $N$ is finite, we require $a_{N, s+N}=k_{N, s+N}=b_{N, s+N}=0$. If $N$ is infinite, we require a household's asset allocation to be essentially bounded from below. ${ }^{17}$ We also require households to choose bounded real allocations.

Households that were born before period 0 solve a similar problem from period 0 onwards, except for their initial condition: a household born in period $j<0$ starts from an (exogenous) initial condition $\left(k_{-j-1,-1}, b_{-j-1,-1}, a_{-j-1,-1}\right)$ that is not necessarily $0 .^{18}$

\subsection{Competitive equilibrium}

A competitive equilibrium is a real allocation $\left\{\left\{\hat{c}_{s, t}, \hat{l}_{s, t}\right\}_{s=0}^{N}, \hat{i}_{t}, \hat{\gamma}_{t}, \hat{G}_{t}, \hat{K}_{t}, \hat{\Gamma}_{t}\right\}_{t=0}^{\infty}$, an asset allocation $\left\{\left\{\hat{k}_{s, t}, \hat{b}_{s, t}, \hat{a}_{s, t}\right\}_{s=0}^{N-1}\right\}_{t=0}^{\infty}$, a tax-debt policy $\left\{\hat{\tau}_{t}, \hat{B}_{t}\right\}_{t=0}^{\infty}$, a price system $\left\{\hat{w}_{t}, \hat{r}_{t}, \hat{p}_{t}, \hat{\pi}_{t}\right\}_{t=0}^{\infty}$, initial

\footnotetext{
${ }^{16}$ This implies that the corresponding terms in (12) can be neglected, and the undefined term $\theta_{-1}$ does thus not appear.

${ }^{17}$ The household's asset allocation is bounded from below if $\left\{k_{t-s, t}, b_{t-s, t}, a_{t-s, t}\right\}_{t=s}^{\infty}$ form a stochastic process that is bounded from below; it is essentially bounded from below if there exists an alternative asset allocation $\left\{\tilde{k}_{t-s, t}, \tilde{b}_{t-s, t}, \tilde{a}_{t-s, t}\right\}_{t=s}^{\infty}$ that is bounded below, satisfies (12) for a suitable bounded choice of $\left\{c_{t-s, t}, l_{t-s, t}\right\}_{t=s}^{\infty}$, and is such that $\left[r_{t}+\left(1-\delta^{k}\right) q_{t}^{k}\right] \tilde{k}_{t-s, t}+\left(p_{t}+1\right) \tilde{b}_{t-s, t}+\tilde{a}_{t-s, t} \leq\left[r_{t}+\left(1-\delta^{k}\right) q_{t}^{k}\right] k_{t-s, t}+\left(p_{t}+1\right) b_{t-s, t}+a_{t-s, t}, t \geq s$.

${ }^{18}$ We also require $\sum_{s=0}^{N-1} \lambda_{s} k_{s,-1}=K_{-1}, \sum_{s=0}^{N-1} \lambda_{s} b_{s,-1}=B_{-1}$ and $\sum_{s=0}^{N-1} \lambda_{s} a_{s,-1}=0$.
} 
conditions $\left\{\left\{k_{-s-1,-1}, b_{-s-1,-1}, a_{-s-1,-1}\right\}_{s=-N}^{-1}, K_{-1}, \Gamma_{-1}, B_{-1}\right\}$, and a transfer sequence $\left\{T_{t}\right\}_{t=-N}^{+\infty}$ such that:

(i) $\left(\left\{\hat{c}_{t-s, t}, \hat{l}_{t-s, t}\right\}_{t=\max (0, s)}^{s+N},\left\{\hat{k}_{t-s, t}, \hat{b}_{t-s, t}, \hat{a}_{t-s, t}\right\}_{t=\max (0, s)}^{s+N-1}\right)$ solves the maximization problem of the representative household born in period $s$, given the price system, the tax policy, the initial conditions, and the transfers;

(ii) at any time $t$, factor prices equal marginal products:

$$
\begin{aligned}
& \hat{w}_{t}=A_{t} F_{l}\left(\frac{\hat{K}_{t-1}}{1+n}, \hat{L}_{t}\right) \\
& \hat{r}_{t}=A_{t} F_{k}\left(\frac{\hat{K}_{t-1}}{1+n}, \hat{L}_{t}\right)
\end{aligned}
$$

(iii) at any time $t$, the allocation satisfies the feasibility conditions (2), (3) and (4);

(iv) at any time $t$, the asset markets clear:

$$
\begin{aligned}
\hat{K}_{t} & =\sum_{s=0}^{N} \lambda_{s} \hat{k}_{s, t} \\
\hat{B}_{t} & =\sum_{s=0}^{N} \lambda_{s} \hat{b}_{s, t} \\
0 & =\sum_{s=0}^{N} \lambda_{s} \hat{a}_{s, t}
\end{aligned}
$$

(v) the government budget constraint holds

$$
\hat{p}_{t} \hat{B}_{t}=\frac{\hat{B}_{t-1}}{1+n}\left(1+\hat{p}_{t}\right)+q_{t}^{G} \hat{G}_{t}+q_{t}^{\Gamma} \hat{\gamma}_{t}-\hat{\gamma}_{t}+\sum_{s=0}^{N} \lambda_{s} T_{t-s}
$$

The necessary conditions of the household maximization problem imply that, in a competitive equilibrium, 19

$$
\begin{gathered}
\hat{p}_{t}=\frac{\beta}{1-\beta}, \quad t \geq 0 \\
1 / \beta=\frac{E_{t}\left(\hat{r}_{t+1}+\left(1-\delta^{k}\right) q_{t+1}^{k}\right)}{q_{t}^{k}}, \quad t \geq 0
\end{gathered}
$$

\footnotetext{
${ }^{19}$ These conditions include the absence of pricing bubbles; see footnote 15.
} 


$$
\begin{gathered}
\beta=\pi_{t}, \quad t \geq 0 \\
\phi^{\prime}\left(l_{s, t}\right)=\hat{w}_{t}, \quad s=0, \ldots, N, t \geq 0
\end{gathered}
$$

and, if $N=\infty$,

$$
\lim _{t \rightarrow \infty} \beta^{t} E_{j}\left\{\left[\hat{r}_{t}+\left(1-\delta^{k}\right) q_{t}^{k}\right] \hat{k}_{t-s, t-1}+\left(\hat{p}_{t}+1\right) \hat{b}_{t-s, t-1}+\hat{a}_{t-s, t}\right\}=0, \quad s \geq 0, \quad j \geq \max \{0, s\}
$$

Because utility is linear in consumption, in any competitive equilibrium, as in any Paretooptimal allocation, individual consumption absorbs the impact of all shocks at time $t$, making history irrelevant. Furthermore, substituting (13) into (17) and (19), we obtain that the labor supply and capital coincide with their values in any Pareto-optimal allocation, and are thus uniquely pinned down and independent of the government spending processes. Working backwards through (13), we obtain that the equilibrium factor prices are also uniquely pinned down; like the labor supply and capital, they are independent of $\left\{G_{t}, \Gamma_{t}\right\}_{t=0}^{\infty}$.

\subsection{Political-economic equilibrium}

Next we define a political-economic equilibrium in which households collectively choose public spending and investment in each period within our institutional framework. To evaluate those choices, households must form expectations about the evolution of the economy. Define a history of the economy to be a sequence $h^{t} \equiv\left\{s_{j}, G_{j}, \Gamma_{j}\right\}_{j=0}^{t}$, for any $t \geq 0 .{ }^{20}$

We define a political-economic equilibrium in terms of a (measurable) mapping $\Psi$ that recursively generates a history of the economy. The mapping $\Psi$ associates to each history $h^{t}$ a time- $t$ allocation (other than public spending and capital, already included in $\left.h^{t}\right)\left(\left\{c_{s}\left(h^{t}\right), l_{s}\left(h^{t}\right)\right\}_{s=0}^{N}, i\left(h^{t}\right)\right.$, $\left.\gamma\left(h^{t}\right), K\left(h^{t}\right)\right)$, a time- $t$ tax-debt policy $\left(B\left(h^{t}\right), \tau\left(h^{t}\right)\right)$, a time- $t$ price vector $\left(w\left(h^{t}\right), r\left(h^{t}\right), p\left(h^{t}\right), \pi\left(h^{t}\right)\right)$, a time- $t$ asset allocation $\left(\left\{k_{s}\left(h^{t}\right), b_{s}\left(h^{t}\right), a_{s}\left(h^{t}\right)\right\}_{s=0}^{N-1}\right)$, and a time- $t+1$ choice of government spending and capital, contingent on the future shock, $\left(G\left(h^{t}, s_{t+1}\right), \Gamma\left(h^{t}, s_{t+1}\right)\right)$. To obtain the time-0 values of government spending and capital, we also associate two values $G(\emptyset)$ and $\Gamma(\emptyset)$ to the

\footnotetext{
${ }^{20}$ Although other variables could be introduced as part of the history, it is easy to show that their presence would be redundant for the definition of an equilibrium below. See e.g. Chari and Kehoe [7].
} 
null history. Given any history $h^{j}$, each mapping $\Psi$ recursively generates a history from $h^{j}$ : $h^{t}=\left(h^{t-1}, s_{t}, G\left(h^{t-1}, s_{t}\right), \Gamma\left(h^{t-1}, s_{t}\right)\right)$. Each mapping $\Psi$ and its associated history induce an allocation, a price system, and a tax/debt policy from initial conditions $\Gamma_{j-1}$, which is part of $h^{j},\left\{k_{s}\left(h^{j-1}\right), b_{s}\left(h^{j-1}\right), a_{s}\left(h^{j-1}\right)\right\}_{s=0}^{N-1}$, and $s_{j}{ }^{21}$

A mapping $\tilde{\Psi} \equiv\left(\left\{\tilde{c}_{s}, \tilde{l}_{s}\right\}_{s=0}^{N},\left\{\tilde{k}_{s}, \tilde{b}_{s}, \tilde{a}_{s}\right\}_{s=0}^{N-1}, \tilde{i}, \tilde{\gamma}, \tilde{K}, \tilde{B}, \tilde{\tau}, \tilde{w}, \tilde{r}, \tilde{p}\right)$ is a political-economic equilibrium if it has the following properties.

(i) (Competitive equilibrium) Given any history $h^{j}$, including the null history, the real and asset allocations, the price system and tax/debt policy induced by $\tilde{\Psi}$ form a competitive equilibrium from the initial conditions $\Gamma_{j-1}, \tilde{K}\left(h^{j-1}\right), \tilde{B}\left(h^{j-1}\right),\left\{\tilde{k}_{s}\left(h^{j-1}\right), \tilde{b}_{s}\left(h^{j-1}\right), \tilde{a}\left(h^{j-1}\right)\right\}_{s=0}^{N-1}$, and $s_{j}$.

(ii) (Self-interested voting) Given any history $h^{j-1}$, including the null, and any shock $s_{j}$, $\left(\tilde{G}\left(h^{j-1}, s_{j}\right), \tilde{\Gamma}\left(h^{j-1}, s_{j}\right)\right)$ is a Condorcet winner over any alternative proposal $(G, \Gamma)$, assuming that in the future the economy will follow the path implied by $\tilde{\Psi}$, i.e., given any alternative $(G, \Gamma)$, the following relation holds for more than $50 \%$ of the people alive at time $j$ :

$$
\begin{aligned}
& \tilde{c}_{s}\left(\tilde{h}_{G, \Gamma}^{j}\right)+v(G, \Gamma)+ \\
& \left.\sum_{t=1}^{N-s} \beta^{t}\left(\prod_{m=s}^{s+t-1} \theta_{m}\right) E_{j}\left[\tilde{c}_{s+t}\left(\tilde{h}_{G, \Gamma}^{j+t}\right)+v\left(\tilde{G}\left(\tilde{h}_{G, \Gamma}^{j+t-1}, s_{t+j}\right)\right), \tilde{\Gamma}\left(\tilde{h}_{G, \Gamma}^{j+t-1}, s_{t+j}\right)\right)\right] \leq \\
& \sum_{t=0}^{N-s} \beta^{t}\left(\prod_{m=s}^{s+t-1} \theta_{m}\right) E_{j}\left[\tilde{c}_{s+t}\left(\tilde{h}^{j+t}\right)+v\left(\tilde{G}\left(\tilde{h}^{j+t-1}, s_{t+j}\right), \tilde{\Gamma}\left(\tilde{h}^{j+t-1}, s_{t+j}\right)\right)\right]
\end{aligned}
$$

where $\tilde{h}_{G, \Gamma}^{j+t-1}$ and $\tilde{h}^{j+t-1}$ are defined recursively as follows:

$$
\begin{gathered}
\tilde{h}_{G, \Gamma}^{j}=\left(h^{j-1}, s_{j}, G, \Gamma\right) \\
\tilde{h}_{G, \Gamma}^{j+t}=\left(\tilde{h}_{G, \Gamma}^{j+t-1}, s_{j+t}, \tilde{G}\left(\tilde{h}_{G, \Gamma}^{j+t-1}, s_{j+t}\right), \tilde{\Gamma}\left(\tilde{h}_{G, \Gamma}^{j+t-1}, s_{j+t}\right)\right), \quad t \geq 1 \\
\tilde{h}^{j+t}=\left(\tilde{h}^{j+t-1}, s_{j+t}, \tilde{G}\left(\tilde{h}^{j+t-1}, s_{j+t}\right), \tilde{\Gamma}\left(\tilde{h}^{j+t-1}, s_{j+t}\right)\right), \quad t \geq 0
\end{gathered}
$$

${ }^{21} h^{j-1}$ is the predecessor of the history $h^{j}$. When we consider an initial history $h^{0}, \tilde{k}_{s}\left(h^{-1}\right)$ is $k_{s,-1}$, the initial level which is exogenously given; the same applies to other variables. 
In words, $\tilde{h}^{j+t}$ is the history induced by $\tilde{\Psi}$ from $h^{j-1} ; \tilde{h}_{G, \Gamma}^{j+t}$ is the history induced by choosing $(G, \Gamma)$ in period $j$ and following $\tilde{\Psi}$ afterwards.

(iii) (Budget balance) Given any non-null history,

$$
\tilde{\tau}\left(h^{t}\right)=\frac{\left(1+\alpha \tilde{p}\left(h^{t}\right)\right) \tilde{B}\left(h^{t-1}\right)}{1+n}+q_{t}^{G} G_{t}+(1-x) q_{t}^{\Gamma} \tilde{\gamma}\left(h^{t}\right)+\sum_{s=0}^{N} \lambda^{s} T_{t-s}
$$

where $G_{t}$ is the appropriate element of the history $h^{t}$.

Requirement (i) states that, no matter what happened in the past, $\tilde{\Psi}$ prescribes a path that is a competitive equilibrium for the households. Requirement (ii) states that at each time $t$ the majority prefers not to deviate from an equilibrium $\tilde{G}, \tilde{\Gamma}$, taking into account that a deviation has an immediate utility impact and also affects the future by changing the path of histories that will unfold. Requirement (iii) embodies the budget rule restrictions (iii), (iv) (v) and (vi) imposed by the constitution.

We focus our attention on a specific class of political-economic equilibria that we will call Markov equilibria, in which the current choices of $G$ and $\Gamma$ are influenced by the minimum possible number of state variables. In our environment with quasilinear preferences, a minimum state description is attained when the choices depend only on the current realization of the shock $s_{t}$.

It is convenient to use

Assumption $1 E_{t}\left(1-\delta_{t+1}^{\Gamma}\right) q_{t+1}^{\Gamma}$ depends only on $s_{t}$.

Assumption 1 is clearly satisfied if $s_{t}$ is a first-order Markov process, but it is a much weaker requirement.

The next proposition shows that, when future choices of $G$ and $\Gamma$ are not conditional on past variables, the same turns out to be optimal for the current choice. ${ }^{22}$

\footnotetext{
${ }^{22}$ Markov equilibria do not allow the government to exploit "trigger-strategy" equilibria, in which failure to deliver a certain amount of public goods in the current period leads households to unfavorable expectations in the future even though the "fundamentals" of the economy are unaffected.
} 
Proposition 1 If assumption 1 holds, there exist Markov equilibria in which $G$ and $\Gamma$ are functions of $s_{t}$ alone. Following any history, all variables are the same in all equilibria, except for the distribution of consumption. Though individual consumption may vary across different equilibria, all generations achieve the same welfare ex ante in all Markov equilibria.

Proof. Our proof works by construction. We proved earlier that all competitive equilibria share the same values of $p_{t}, K_{t}, w_{t}, r_{t}$ and $l_{s, t}$, for any $s, t \geq 0$, and that these are independent of $\left\{G_{t}, \Gamma_{t}\right\}_{t=0}^{\infty}$. This implies that, for any history $h^{t}$, there is a unique way to set $p\left(h^{t}\right), K\left(h^{t}\right), w\left(h^{t}\right)$, $r\left(h^{t}\right)$ and $l_{s}\left(h^{t}\right), s \geq 0$, and that all these variables are functions of the history of exogenous shocks only. We set investment to the only values that are consistent with (3) and (4): $i\left(h^{t}\right)=$ $K\left(h^{t}\right)-\left(1-\delta^{k}\right) K\left(h^{t-1}\right)$ and $\gamma\left(h^{t}\right)=\Gamma_{t}-\left(1-\delta_{t}^{\Gamma}\right) \Gamma_{t-1}$.

To get the values of $G\left(h^{t-1}, s_{t}\right)$ and $\Gamma\left(h^{t-1}, s_{t}\right)$, we proceed as follows. In the candidate equilibrium we are constructing, future levels of public spending and capital are unaffected by the current ones. Within the equilibrium, an increase in the time- $t$ provision of either public good benefits only the households that are alive in period $t$. On the cost side, equations (15) and (22) imply that an additional unit of $G_{t}$ increases time- $t$ taxes by $q_{t}^{G}$ units, with no effect on subsequent taxes. An additional unit of $\gamma_{t}$ increases time- $t$ taxes by $q_{t}^{\Gamma}(1-x)$. Within the candidate equilibrium, the additional unit leads to a reduction in $\gamma_{t+1}$ of $\left(1-\delta_{t+1}^{\Gamma}\right) /(1+n)$ units, and no further effect on public investment. This implies that time- $t+1$ taxes change by

$$
\frac{x q_{t}^{\Gamma}}{1+n}\left(\frac{1-\beta}{\beta}+\alpha\right)-\frac{q_{t+1}^{\Gamma}(1-x)\left(1-\delta_{t+1}^{\Gamma}\right)}{1+n}
$$

and taxes in period $t+j, j>1$ by

$$
\frac{x}{(1+n)^{j}}\left[\frac{1-\beta}{\beta}+\alpha\right]\left[q_{t}^{\Gamma}(1-\alpha)-q_{t+1}^{\Gamma}\left(1-\delta_{t+1}^{\Gamma}\right)\right](1-\alpha)^{j-2} .
$$

To a person of age $s$, the expected present value of taxes per unit of public capital is therefore

$$
\begin{aligned}
Q_{s} \equiv & q_{t}^{\Gamma}(1-x)+\frac{\beta \theta_{s}}{1+n}\left[x q_{t}^{\Gamma}\left(\frac{1-\beta}{\beta}+\alpha\right)-(1-x) E_{t}\left[q_{t+1}^{\Gamma}\left(1-\delta_{t+1}^{\Gamma}\right)\right]\right]+ \\
& \sum_{j=2}^{N-s} \beta^{j}\left(\prod_{m=s}^{s+j-1} \theta_{m}\right) \frac{x}{(1+n)^{j}}\left[\frac{1-\beta}{\beta}+\alpha\right]\left[q_{t}^{\Gamma}(1-\alpha)-E_{t}\left[q_{t+1}^{\Gamma}\left(1-\delta_{t+1}^{\Gamma}\right)\right]\right](1-\alpha)^{j-2} .
\end{aligned}
$$


The preferences over policy for this person are given by

$$
v(G, \Gamma)-q_{t}^{G} G-Q_{s} \Gamma
$$

If we order households by $Q_{s}$, the preferences above satisfy the order restriction of Rothstein [27, 28], which implies that a Condorcet winner exists, and that it corresponds to the policy preferred by the person with median $Q_{s} \cdot{ }^{23}$ We thus set $G\left(h^{t-1}, s_{t}\right)$ and $\Gamma\left(h^{t-1}, s_{t}\right)$ to

$$
\arg \max _{G, \Gamma} v(G, \Gamma)-q_{t}^{G} G-\operatorname{median}\left(Q_{s}\right) \Gamma
$$

Given our assumptions, a unique solution to this problem exists, and it depends only on $s_{t}$. For any non-null history, we set $B$ recursively:

$$
B\left(h^{t}\right)=\frac{(1-\alpha) B\left(h^{t-1}\right)}{1+n}+\frac{x q_{t}^{\Gamma} \gamma\left(h^{t}\right)}{p\left(h^{t}\right)} .
$$

We set $\tau\left(h^{t}\right)$ according to $(22)$, and aggregate consumption such that

$$
\sum_{s=0}^{\infty} \lambda_{s} c_{s}\left(h^{t}\right)=A_{t} F\left(\frac{K\left(h^{t-1}\right)}{1+n}, l\left(h^{t}\right)\right)-q_{t}^{k} i\left(h^{t}\right)-q_{t}^{G} G_{t}-q_{t}^{\Gamma} \gamma\left(h^{t}\right) .
$$

Subject to (26), individual consumption is not uniquely pinned down.

To construct individual consumption, we partition the set of histories into stochastic sequences $\left\{h^{v}\right\}_{v=t}^{\infty}, t \geq-1$, with the property that, within elements of the same partition, $h^{v}=\left(h^{v-1}, s_{v}, G\left(h^{v-1}, s_{v}\right), \Gamma\left(h^{v-1}, s_{v}\right)\right)$ for an arbitrary value of the shock $s_{v}$, while for each initial element of a sequence either $t=-1$ or $h^{t} \neq\left(h^{t-1}, s_{t}, G\left(h^{t-1}, s_{t}\right), \Gamma\left(h^{t-1}, s_{t}\right)\right)$. Within each partition, a history represents a path that is induced by the functions $G($.$) and \Gamma($.$) from the$ history $h^{t}$. Along each of these paths, we set the functions $c_{s}(),. k_{s}(),. b_{s}($.$) and a_{s}($.$) arbitrarily,$ subject to the following restrictions:

(i) Given the taxes and prices specified above, the resulting sequences must satisfy the household budget constraints (12) for an economy that starts in period $t$ with initial conditions specified by $\left(k_{s}\left(h^{t-1}\right), b_{s}\left(h^{t-1}\right), a_{s}\left(h^{t-1}\right)\right)_{s=0}^{N-1}$;

\footnotetext{
${ }^{23}$ In computing the median, it is of course necessary to take into account the distribution of the population by age. The same qualification pertains to all other references to the median in the paper.
} 
(ii) if $N=\infty$, the implied asset allocation must be essentially bounded from below;

(iii) the implied real allocation must be bounded;

(iv) individual consumption schedules are such that (26) holds in the aggregate.

Examples of functions that satisfy these requirements are the following: ${ }^{24} k_{s}\left(h^{v}\right)=K\left(h^{v}\right) /(1-$ $\left.\lambda_{N}\right), b_{s}\left(h^{v}\right)=B\left(h^{v}\right) /\left(1-\lambda_{N}\right), a_{s}\left(h^{v}\right)=0$ and

$$
\begin{aligned}
& c_{s}\left(h^{v}\right)=-\frac{q_{v}^{k} K\left(h^{v}\right)+p\left(h^{v}\right) B\left(h^{v}\right)}{1-\lambda_{N}}+w\left(h^{v}\right) l_{s}\left(h^{v}\right)-\tau\left(h^{v}\right)+T_{v-s} \\
& +\frac{\left[r\left(h^{v}\right)+\left(1-\delta^{k}\right) q_{v}^{k}\right] K\left(h^{v-1}\right)}{\theta_{s-1}\left(1-\lambda_{N}\right)}+\frac{\left(p\left(h^{v}\right)+1\right) B\left(h^{v-1}\right)}{\theta_{s-1}\left(1-\lambda_{N}\right)}, \quad v>0, s=1, \ldots, N-1 \\
& c_{s}\left(h^{0}\right)=-\frac{q_{0}^{k} K\left(h^{0}\right)+p\left(h^{0}\right) B\left(h^{0}\right)}{1-\lambda_{N}}+w\left(h^{0}\right) l_{s}\left(h^{0}\right)-\tau\left(h^{0}\right)+T_{-s} \\
& +\frac{\left[r\left(h^{0}\right)+\left(1-\delta^{k}\right) q_{0}^{k}\right] k_{s-1,-1}}{\theta_{s-1}}+\frac{\left(p\left(h^{0}\right)+1\right) b_{s-1,-1}}{\theta_{s-1}}+\frac{a_{s-1,0}}{\theta_{s-1}}, \quad s=1, \ldots, N-1 \\
& c_{0}\left(h^{v}\right)=-\frac{q_{t}^{k} K\left(h^{v}\right)+p\left(h^{v}\right) B\left(h^{v}\right)}{1-\lambda_{N}}+w\left(h^{v}\right) l_{0}\left(h^{v}\right)-\tau\left(h^{v}\right)+T_{v}, \quad v \geq 0 \\
& c_{N}\left(h^{v}\right)=w\left(h^{v}\right) l_{N}\left(h^{v}\right)-\tau\left(h^{v}\right)+T_{v-N} \\
& +\frac{\left[r\left(h^{v}\right)+\left(1-\delta^{k}\right) q_{v}^{k}\right] K\left(h^{v-1}\right)}{\theta_{N-1}\left(1-\lambda_{N}\right)}+\frac{\left(p\left(h^{v}\right)+1\right) B\left(h^{v-1}\right)}{\theta_{N-1}\left(1-\lambda_{N}\right)}, \quad v>0, \\
& c_{N}\left(h^{0}\right)=w\left(h^{0}\right) l_{N}\left(h^{0}\right)-\tau\left(h^{0}\right)+T_{-N} \\
& +\frac{\left[r\left(h^{0}\right)+\left(1-\delta^{k}\right) q_{0}^{k}\right] k_{N-1,-1}}{\theta_{N-1}}+\frac{\left(p\left(h^{v}\right)+1\right) b_{N-1,-1}}{\theta_{N-1}}+\frac{a_{N-1,0}}{\theta_{N-1}} .
\end{aligned}
$$

By iterating equation (25) forward and using the facts that $p\left(h^{v}\right)$ is constant over time and that $\Gamma\left(h^{v}\right)$ is bounded, we can show that $B\left(h^{v}\right)$ is bounded, which implies that the consumption plans of the households are bounded. ${ }^{25}$

It is now straightforward to see that the mapping that we have just constructed generates a competitive equilibrium starting from any history $h^{j}$, given the levels of public spending and capital implied by (24). Starting from any initial capital level, we previously showed that the

\footnotetext{
${ }^{24}$ If $N=\infty, \lambda_{N}$ should be set to 0 , and (30) and (31) do not apply.

${ }^{25}$ If $N=+\infty$, the proposed asset allocation also satisfies the no-Ponzi games restriction and the transversality condition (20).
} 
values assigned to $p\left(h^{t}\right), \pi\left(h^{t}\right), K\left(h^{t}\right), l_{s}\left(h^{t}\right), w\left(h^{t}\right)$ and $r\left(h^{t}\right), t \geq j$, are the unique choices that ensure that the household problem has a (bounded) solution, that factor prices equal marginal products, that the labor supply is optimally chosen, and that (16) and (18) hold. With these choices, households are indifferent among all possible consumption profiles. Given the previously determined variables and (22), equation (25) describes the unique sequence of government debt that satisfies the government budget constraint and (20), and (26) describes the unique sequence of aggregate consumption that is consistent with the resource constraint (2). The conditions on the consumption of individual households ensure that the individual budget constraints are met. Whenever the future levels of $G$ and $\Gamma$ depend only on the future shocks and not on any history, the mapping constructed above implies that the current choices of $G$ and $\Gamma$ do not affect the labor supply, private capital, or factor prices in any period, nor do they affect subsequent values of public spending and capital. These are precisely the conditions under which households will vote for $G$ and $\Gamma$ according to (24), which implies that the mapping satisfies condition (ii) of a political-economic equilibrium. Finally, condition (iii) is met because it was imposed in the construction of the mapping.

To check that all Markov equilibria lead to the same ex ante welfare for all generations, notice that prices, taxes, and the provision of the public goods are the same in all Markov equilibria and in all histories. As a consequence, the individual household's optimization problem is identical in all of the equilibria, and the multiplicity of the Markov equilibria comes only from the fact that households are indifferent among many equivalent optimal consumption plans. QED.

From now on, we will refer to "the" Markov equilibrium, ignoring the multiplicity that is irrelevant for the aggregate allocation and for welfare. We are interested in comparing the equilibrium outcome with Pareto-optimal allocations.

Proposition 2 The Markov equilibrium outcome satisfies conditions (7), (9) and (10) of Pareto efficiency.

Proof. We already observed that any competitive equilibrium satisfies (9) and (10). (7) is the first-order (necessary and sufficient) condition for maximizing (24) with respect to G. QED. 
With quasilinear preferences, the level of public consumption $G$ will be efficient if households are forced to pay for it through contemporaneous taxes. This result carries a nice intuition: a balanced-budget restriction over (nondurable) public consumption converts the choice of its level into a static decision. All households alive agree on the benefits, and they also equally share the costs, leading to an efficient decision. ${ }^{26}$

The next proposition shows that a pure balanced-budget rule leads to underprovision of public capital for the most relevant range of parameter values.

Proposition 3 Assume that median $\left(\theta_{s}\right)<1+n$. Then, if $x=0$, the marginal value of public capital in the Markov equilibrium outcome is higher than the efficient level implied by (8).

Proof. When $x=0, Q_{s}=q_{t}^{\Gamma}-\frac{\theta_{s} \beta E_{t}\left[\left(1-\delta_{t+1}^{\Gamma}\right) q_{t+1}^{\Gamma}\right]}{1+n}$. Under the assumption that median $\left(\theta_{s}\right)<$ $1+n$, the proposition follows immediately. $Q E D$.

Since $\theta_{s} \leq 1$, the hypothesis of proposition 3 is valid whenever there is any population growth. The hypothesis of the proposition fails only if population shrinks faster than the median probability of survival.

Assumption $2 Q_{s}$ is strictly decreasing in $x$ for all ages $s$.

Lemma 1 A sufficient condition for assumption 2 is that $\theta_{s}<1+n$ for all ages $s$ and $q_{t}^{\Gamma}(1-\alpha)>$ $E_{t}\left[q_{t+1}^{\Gamma}\left(1-\delta_{t+1}^{\Gamma}\right)\right] \cdot{ }^{27}$

Proving the lemma is a matter of simple but tedious algebra. The condition in the lemma relates the repayment rate of debt $(\alpha)$ to the depreciation of public capital $\left(\delta_{t+1}^{\Gamma}\right)$. When $E_{t}\left[q_{t+1}^{\Gamma}(1-\right.$ $\left.\left.\delta_{t+1}^{\Gamma}\right)\right]=q_{t}^{\Gamma}\left(1-E_{t} \delta_{t+1}^{\Gamma}\right)$, this condition reduces to $\alpha \leq E_{t} \delta_{t+1}^{\Gamma}$, and is satisfied if debt is repaid more slowly than the rate at which capital depreciates. In the more-general case, the condition requires the expected value of undepreciated capital 1 period after the investment to be less than the amount of debt contracted at time $t$ and left to be paid off after period $t+1$. Once again, the condition is thus satisfied when debt is repaid sufficiently slowly. If the issued debt

\footnotetext{
${ }^{26}$ See Wallis [34] and Wallis and Weingast [35] for descriptions of explicit discussions of 'benefit taxation' in the U.S. during the 1800 s.

${ }^{27}$ If $\theta_{s}<1 \forall s$, then the sufficient condition holds even if the inequality is weak, rather than strict.
} 
becomes due too fast, it is possible for the debt actually to increase the amount of taxes per unit of current investment that some households pay, taking into account the future equilibrium response of investment. Whether this perverse case arises depends not only on $\alpha$ and $\delta_{t+1}^{\Gamma}$, but also on the details of the stochastic death process. For some stochastic processes, such as the constant probability of death considered later, allowing debt always reduces the perceived cost.

Proposition 4 Let median $\left(\theta_{s}\right)<1+n$ and assumption 2 hold. Then there exists a level $\bar{x}>0$ such that the marginal value of public capital in the equilibrium outcome when $x=\bar{x}$ is almost surely closer to the efficient level than if $x \leq 0$.

Proof. Proposition 3 established that $v_{\Gamma}\left(G_{t}, \Gamma_{t}\right)$ is higher than the efficient level when $x \leq 0$. Assumption 2 implies that median $\left(Q_{s}\right)$ is strictly decreasing in $x$, and hence the same is true of the equilibrium value of $v_{\Gamma}\left(G_{t}, \Gamma_{t}\right)$. $Q E D$.

Proposition 4 provides a sufficient condition for the desirability of setting $x>0$ in the constitution. $^{28}$ Intuitively, the ability partly to finance public investment through debt is useful if it reduces the cost perceived by the voters alive at the moment in which the decision is taken.

In the next proposition, we tailor $x$ exactly to match the solution that comes from maximizing (24) subject to the efficiency condition (8). In general, the best $x$ will depend on $t$ and $s_{t}$, so it is impossible to reach efficiency if the constitution specifies a fixed $x$. However, a fixed $x$ will work under the following:

Assumption $3 E_{t}\left(1-\delta_{t+1}^{\Gamma}\right) q_{t+1}^{\Gamma}=\left(1-\bar{\delta}^{\Gamma}\right) q_{t}^{\Gamma}$ almost surely.

A simple example in which assumption 3 holds is when $q_{t}^{\Gamma}$ is nonstochastic and constant over time and $\delta_{t}^{\Gamma}$ is i.i.d. We will later consider the quantitative costs of deviating from the optimal

\footnotetext{
${ }^{28}$ We reason here in terms of pure efficiency, but different choices of $x$ also have distributional implications. Suppose for instance that the economy is initially in an equilibrium with $x=0$, and that an unexpected reform sets it to a positive value that leads to a more-efficient provision of public capital. While everybody potentially benefits from this increased efficiency, the reform will generate an increase in public debt that can hurt generations born far in the future. Therefore, this reform is not necessarily a Pareto improvement unless transfers are adjusted to compensate future generations.
} 
$x$; those computations will indirectly inform us about the magnitude of the efficiency losses of adopting a fixed value for $x$ in the constitution when assumption 3 fails.

Proposition 5 Let assumption 3 hold. Then, generically in the death process, there exists a value $x^{*}$ such that, if $x=x^{*}$, the allocation induced by any Markov equilibrium is Pareto optimal. A sufficient condition for $x^{*}$ to be unique is that assumption 2 holds.

Proof. See appendix.

Little can be said in general about how $x^{*}$ varies with the parameters of the model. It follows immediately from theorem 4 that $x^{*}>0$ when the assumptions of the theorem hold; otherwise, even its sign cannot be established a priori. We now consider two special cases in which strong implications can be derived.

Assumption 4 Let $N=\infty$ and $\theta_{s}=\bar{\theta}, s=0, \ldots$

Assumption 4 corresponds to the overlapping generation model of Blanchard [3], in which all households face a constant probability of death, independent of age. This case is interesting not only as a benchmark, but also because it informs us of properties that will be shared by the quantitative calibrations of the next subsection. This happens because the probability of dying in the next year is small for most people, and very slowly increasing with age; only in very old age does the probability increase substantially, but those elderly people turn out to be far from the median voter, and thus have no direct influence over the outcome.

Proposition 6 Let assumptions 3 and 4 hold. Then households' preferences over $(G, \Gamma)$ are independent of age, and

$$
x^{*}=\frac{\beta\left(1-\bar{\delta}^{\Gamma}\right)(1-\beta \theta(1-\alpha) /(1+n))}{1-\beta \theta\left(1-\bar{\delta}^{\Gamma}\right) /(1+n)}>0 .
$$

Proof. It follows from simple algebra. First, substitute assumptions 2 and 4 in the definition of $Q_{s}$. The resulting value is independent of $s$. We then solve (24), and match its first-order conditions to (8). QED.

With quasilinear preferences, the only disagreement among households comes from the different probabilities of surviving into future periods. In the Blanchard model, these probabilities 
are the same, and the policy vote becomes unanimous once again. Furthermore, under the Blanchard assumption, issuing debt necessarily lowers the perceived cost of public capital for all people alive; it follows that the optimal level of debt financing is positive.

From (32), a higher depreciation of public capital implies that the efficient debt financing is smaller, as one would expect. The effect of increasing the probability of survival $\theta$ and/or decreasing population growth $n$ is ambiguous. Both opposing effects become less prominent when $\theta /(1+n)$ approaches $1 .{ }^{29}$ The optimal level of $x$ does not converge to 0 as $\theta /(1+n)$ converges to 1 ; however, the inefficiency caused by a given $x$ vanishes in the limit as $\theta /(1+n) \rightarrow 1$, because then Ricardian equivalence holds, and it implies that any debt structure would deliver a Pareto-optimal outcome.

Assumption $5 \alpha=\bar{\delta}^{\Gamma}$.

Proposition 7 Let assumptions 3 and 5 hold. Then the value of $x^{*}$ of proposition 5 is equal to $\beta\left(1-\bar{\delta}^{\Gamma}\right)$. Furthermore, when $x$ is set at this value, the household preferences over $(G, \Gamma)$ are independent of age.

Proof. It follows immediately from substituting the relevant values into (24). In particular, with these substitutions $Q_{s}$ is independent of the age s. $Q E D$.

Several authors have stressed the importance of matching the maturity of debt to be issued to the durability of the public investment undertaken, under the principle of "making people pay for what they enjoy." ${ }^{30}$ When $\alpha \neq \bar{\delta}^{\Gamma}$, the 1800 s rule does not conform so precisely to the principle of making people pay for what they enjoy, yet it can still attain an efficient outcome. For efficiency considerations, it is not important to match (marginal) costs and benefits of current investment for each individual cohort, whether born or unborn; it is necessary only to match marginal expected costs and expected benefits for the median voter among the cohorts that take part in the investment decision, i.e., only those alive at the time the investment is undertaken.

While our main analysis shows that matching debt maturity to project durability is not necessary to achieve efficiency, proposition 7 offers a justification for aiming for a match. Choosing

\footnotetext{
${ }^{29}$ The optimal amount of debt is decreasing in $\theta /(1+n)$ if and only if $\bar{\delta}^{\Gamma}>\alpha$.

${ }^{30}$ See e.g. Secrist [30].
} 
to repay debt at the same rate at which capital depreciates avoids conflicts among different generations simultaneously alive; furthermore, it makes it easier to determine the appropriate level of debt to be issued as simply equalling the expected present value of future undepreciated capital. In the absence of uncertainty, this policy is equivalent to requiring generations alive in any period to pay only for the "rental price" of public capital. ${ }^{31}$ More generally, we have the following:

Proposition 8 Suppose that public capital can be owned by private firms and rented to the government at competitive rates. Then an efficient allocation could be achieved by imposing a pure balanced budget requirement on the government, which would rent the services of capital.

We relegate to the appendix the full details of the proof, but the intuition is very straightforward. With a rental market and a pure balanced budget, households alive will agree that it is preferable for the government to rent, rather than own, its public capital. Purchasing the capital would simply be a gift to future generations. Since all generations alive agree on the value of services of public capital within each period, if the rental market is competitive, they will equalize the marginal utility of the services from public capital to the rental price. Anticipating this, firms will have an incentive to buy and rent to the government exactly the efficient amount of capital.

In practice, most components of public capital would not support a competitive rental market because they would generate a severe holdup problem. ${ }^{32}$ The 1800 s rule provides a good alternative to the missing rental market.

\footnotetext{
${ }^{31}$ With uncertainty, this is only true in expected value; later generations may be called to pay more or less, depending on the realization of the shocks.

${ }^{32}$ The following examples illustrate the problem. Any major infrastructure project, such as a canal, would necessarily not face competition from a perfect substitute, generating monopoly power on the supply side. On the demand side, no private firm would be allowed to bid against the government for renting nuclear missiles, generating monopsony.
} 


\section{Calibrated Examples}

The previous theoretical results suggest that financing some, but not necessarily 100\%, of public investment with debt is desirable. If we interpret the 1800s rule as prescribing that $100 \%$ of the cost of public investment be financed by debt issue, it is interesting to inquiry of our model: how close is the efficient debt allowance $x^{*}$ to $100 \%$ ? And what is the efficiency loss from not setting $x$ exactly to $x^{*}$ ?

To answer these questions, we now consider three calibrated examples. Throughout the three examples, we assume:

- A constant, certain value for $q_{t}^{\Gamma}$ (the magnitude is irrelevant);

- Decisions are taken every year, so 1 year is the appropriate period length;

- $\beta=0.96$;

- $\alpha=0.04522$, corresponding to a half-life of debt of 15 years;

- For depreciation, we consider a low value of $\bar{\delta}^{\Gamma}=0.03$ and a high value of $\bar{\delta}^{\Gamma}=0.06$. The former is meant to capture depreciation for major infrastructure projects, the latter is a number commonly used for private capital.

The three examples differ in their demographic structures: ${ }^{33}$

1. For "U.S. now," we calibrate the survival process and the age distribution to that faced by the U.S. population in 2000.

2. For "U.S. 1880", we calibrate the survival process and the age distribution to that faced by the U.S. population in 1880. We will use this example to see to what extent demographic changes over the last two centuries affect the relevance of the "1800s rule."

3. To consider how federal and state governments are affected differently by the budget rule, we calibrate the age structure to that of Illinois in $2000 .{ }^{34}$ We will label this experiment as

\footnotetext{
${ }^{33}$ The details of the demographic structure are contained in appendix B.

${ }^{34}$ The results presented here differ slightly from the earlier version of this working paper. This discrepancy is due to correcting a mistake in computing the mobility by age.
} 
"Illinois now." The crucial difference between "U.S. now" and "Illinois now" is the degree of mobility. The model probability of "death" is calibrated by summing the probability of dying and that of moving out of the state. ${ }^{35}$ We assume that migration decisions are exogenous. Modelling mobility as endogenous would strengthen our results: without borrowing, current generations would have even less of an incentive to invest in public capital, since additional investment would trigger more immigration, congesting any future benefits that the current generations might enjoy. ${ }^{36}$ However, this effect is likely to be swamped by the migration flows that occur for reasons that are independent of taxes and benefits. ${ }^{37}$

$\begin{array}{lccc} & \text { U.S. Now } & \text { U.S. 1880s } & \text { Illinois Now } \\ \bar{\delta}^{\Gamma}=0.03 & 114 \% & 108 \% & 108 \% \\ \bar{\delta}^{\Gamma}=0.06 & 77 \% & 80 \% & 80 \%\end{array}$

Table 1: Optimal Amount of Debt Financing

Table 1 reports the optimal fraction of public investment that should be financed by debt. ${ }^{38}$ The main conclusion that we draw from this table is that this fraction is not very sensitive to the demographic structure and evolution of the population: it is about the same in a calibration with low population growth and low mortality rate (U.S. now), high population growth and high mortality rate (U.S. in 1880) and low population growth with high mobility rate (Illinois now). By contrast, the table shows that the debt is sensitive to the depreciation rate. The results support the case for distinguishing between very long-term investments, such as major infrastructures, and investment in equipment, for which a lower degree of debt financing or a shorter maturity of debt is warranted.

\footnotetext{
${ }^{35}$ It is straightforward to adjust the model to account for migration. Immigration requires assuming that some households are born at ages greater than 0; out-migration requires adjusting the annuitization so that households lose their private assets if they die, but not if they move out of state. Both adjustments do not affect the computations developed above to establish efficiency of the provision of public goods.

${ }^{36}$ See e.g. Schultz and Sjöström [29].

${ }^{37}$ As an example, even for the very targeted AFDC transfer programs, Meyer [16] and Gelbach [10] find that endogenous mobility, while present, has a quantitatively small impact on the programs.

${ }^{38}$ Even when $\alpha<\bar{\delta}^{\Gamma}$, in all of the calibrated examples assumption 2 holds, which implies that $x^{*}$ is unique.
} 
Tables 2 and 3 measure the efficiency wedge in the provision of public capital for a given level of debt financing. This is defined as

$$
\text { Wedge }=\frac{\text { Meq }- \text { Mopt }}{\text { Mopt }}
$$

where Meq $=$ marginal value of public capital in the political-economic equilibrium outcome and Mopt $=$ marginal value of public capital in an efficient allocation. As an example, a reading of $50 \%$ means that only those public infrastructures would be financed that generate a present value of benefits of more than $\$ 1.50$ per $\$ 1$ invested. ${ }^{39}$

In table 2, we consider the consequences of adopting a balanced budget provision that forbids the government ever to borrow. Given the absence of wealth effects, this table also shows the consequences of adopting any rule in which the deficit limit is independent of current spending; a prominent example of this rule is the European stability pact, which caps deficits at 3\% of GDP independently of public spending. The table shows that the efficiency losses from this type of policy can be substantial. It is smallest for current U.S. demographics, which are much closer to Ricardian equivalence, ${ }^{40}$ and larger for 1880 s demographics or the case of Illinois. These results provide a rationale for adopting the 1800s rule in the 18th and 19th century rather than now, and for adopting the rule at the state and local level rather than at the national level.

Table 3 looks at the consequences of allowing public investment to be $100 \%$ debt financed. The main conclusion to be drawn from this table is that the efficiency losses from not tailoring debt financing exactly are quite small; the worst loss comes from the 1880s calibration with $\delta=0.06$, where projects are undertaken if they generate a present value of benefits of $\$ 0.92$ per $\$ 1$ invested.

\footnotetext{
${ }^{39}$ An alternative measure of the costs and benefits of switching policy is cast in (private) consumption equivalents. Using the calibration presented in appendix B.2, the cost estimates turn out to be quite small. As an example, for $\delta=0.06$, the welfare gain, aggregated across generations, from moving from a balanced budget to the efficient policy is a permanent increase of about $0.01 \%$ of consumption for the U.S. government, and of about $0.09 \%$ of consumption for Illinois. These small magnitudes are not surprising, since public investment is a small fraction of GDP; even if all of public investment were pure waste, the consumption cost would simply be its share in GDP, about $1 \%$ for the federal government and $2 \%$ for Illinois.

${ }^{40}$ A calibration to European data, with even lower population growth, would lead to even lower efficiency losses.
} 


$\begin{array}{lccc} & \text { U.S. Now } & \text { U.S. 1880s } & \text { Illinois Now } \\ \bar{\delta}^{\Gamma}=0.03 & 20 \% & 46 \% & 43 \% \\ \bar{\delta}^{\Gamma}=0.06 & 14 \% & 32 \% & 30 \%\end{array}$

Table 2: Efficiency Wedge $=\frac{\text { Meq-Mopt }}{\text { Mopt }}$ under Balanced-Budget

$\begin{array}{lccc} & \text { U.S. Now } & \text { U.S. 1880s } & \text { Illinois Now } \\ \bar{\delta}^{\Gamma}=0.03 & 3 \% & 3 \% & 3 \% \\ \bar{\delta}^{\Gamma}=0.06 & -4 \% & -8 \% & -7 \%\end{array}$

Table 3: Efficiency Wedge under 100\% Debt Financing for Capital Improvements

\section{Conclusions}

Our main lesson is that the 1800s rule does remarkably well, given its simplicity. The rule makes only a blunt distinction between recurring expenses and capital improvements, and permits no debt to pay for the former and $\mathbf{1 0 0 \%}$ debt to pay for the latter. By contrast, the distortions from not distinguishing between the two types of spending can be substantial. This happens even though the only source of "shortsightedness" in the political system comes from population growth and mobility/mortality, which generate only small deviations from Ricardian equivalence.

Bigger departures from Ricardian equivalence are generated by political-economy models with politicians who act as if they are more short-sighted than voters. ${ }^{41}$ Some of these models may be easily extended to strengthen the case for adopting a rule, ${ }^{42}$ while others do not clearly generate a distinction between government spending in durable and nondurable goods. ${ }^{43} \mathrm{~A}$ more systematic

\footnotetext{
${ }^{41}$ Chari and Miller [8] rely on these models in their informal discussion to advocate the adoption at the federal level of the rule considered here.

${ }^{42}$ We view extensions of Rogoff and Sibert [26] and Rogoff [25] as particularly good candidates because they imply a tendency to choose projects with immediate benefits over projects with delayed benefits.

${ }^{43}$ Among these, the most natural extension of models of partisan politics such as Alesina and Tabellini [1], Persson and Svensson [19], or Tabellini and Alesina [33] would generate overspending in both types of goods, unless government capital is perceived as a less partisan good than nondurable consumption, as assumed by Peletier, Dur and Swank [18] and by Azzimonti-Renzo [2].
} 
analysis of the performance of the 1800s rule in such environments is a worthwhile extension of the research we pursued here.

Throughout this paper, we have taken for granted that it is easy to distinguish between durable and nondurable public goods. However, the 1800s rule seems to generate an obvious incentive to label any government expense as a "capital improvement." An alternative institutional setup that is immune to this is explored by Rangel [24], who advocates requiring the government to rely on land taxes alone. ${ }^{44}$ When the value of government capital is factored into the price of land, this approach allows current landowners to reap the benefits of public investments that will accrue to future generations. Local jurisdictions in the U.S. rely heavily on property taxes (if not land taxes), ${ }^{45}$ suggesting that this is may be a viable alternative at least in the case of local public goods.

\section{Appendix}

\section{A Proofs}

\section{A.1 Proof of proposition 5}

We already observed that in a competitive equilibrium the labor supply as well as private capital and investment are equal to their (unique) value implied by any Pareto-optimal allocation. We also proved that the balanced-budget restriction on $G_{t}$ ensures that $(7)$ is satisfied. We need only to prove that there exists a value $x^{*}$ such that the solution to (24) satisfies (8). First, note that $Q_{s}$ is linear in $x$. Matching the first-order condition of (24) with respect to $\Gamma$ to (8) requires

$$
\operatorname{median}\left(Q_{s}^{0}+Q_{s}^{1} x\right)=q_{t}^{\Gamma}\left[1-\beta\left(1-\bar{\delta}^{\Gamma}\right)\right]
$$

where

$$
Q_{s}^{0} \equiv q_{t}^{\Gamma}\left[1-\frac{\beta \theta_{s}\left(1-\bar{\delta}^{\Gamma}\right)}{1+n}\right]
$$

\footnotetext{
${ }^{44} \mathrm{~A}$ similar argument appears also in Glaeser [11].

${ }^{45}$ In terms of efficiency, property taxes and land taxes have very different implications, as the former includes a distortionary tax on capital.
} 
and

$$
\begin{aligned}
Q_{s}^{1} & \equiv q_{t}^{\Gamma}\left\{-1+\frac{\beta \theta_{s}}{1+n}\left[\frac{1}{\beta}+\alpha-\bar{\delta}^{\Gamma}\right]+\right. \\
& \left.\sum_{j=2}^{N-s} \beta^{j}\left(\prod_{m=s}^{s+j-1} \theta_{m}\right) \frac{1}{(1+n)^{j}}\left[\frac{1-\beta}{\beta}+\alpha\right]\left(\bar{\delta}^{\Gamma}-\alpha\right)(1-\alpha)^{j-2}\right\}
\end{aligned}
$$

For a generic death process, we have median $\left(Q_{s}^{1}\right) \neq 0$. In this case, the left-hand side of equation (33) is a continuous function of $x$, and it diverges to infinity as $x$ diverges, but with opposite signs as $x \rightarrow-\infty$ or $x \rightarrow+\infty$. This implies that a solution to equation (33) exists. If assumption 2 holds, then $Q_{s}^{1}<0$ for all ages, hence the median cost strictly decreases with $x$ and the solution is unique. $Q E D$.

\section{A.2 Proof of proposition 8}

Assume the government is constrained by a pure balanced budget. First, we guess and verify that there is a Markov equilibrium in which the government chooses not to own any public capital, the total amount of public capital (rented + owned, in case a deviation occurs and some of it is purchased) is independent of the past (it only depends on the current shocks), and likewise public consumption is independent of the past. The proof repeats the steps of proposition 1 with the following added considerations.

1. The competitive rental price of capital that allows firms to break even equals

$$
q_{t}^{\Gamma}-\beta E_{t}\left[\left(1-\delta_{t+1}^{\Gamma}\right) q_{t+1}^{\Gamma}\right]
$$

This will be the rental rate in any period and after any history.

2. Within a period, the generations alive have to decide how to split the services of public capital that they decide to consume between the rental market and the market where the government purchases the capital. Within the candidate equilibrium, a purchase of public capital by the government will be undone in the next period, when the undepreciated portion will be resold to private firms (and rented back from them). Given the balanced budget requirement, purchasing one unit of capital, rather than renting it, implies an 
increase in taxes of $\beta E_{t}\left[\left(1-\delta_{t+1}^{\Gamma}\right) q_{t+1}^{\Gamma}\right]$ in period $t$, and a decrease of $\frac{1-\delta_{t+1}^{\Gamma}}{1+n} q_{t+1}^{\Gamma}$ next period, with no further consequences. All generations alive will thus prefer that the government rent public capital, as long as either $n>0$ or the probability of survival from period $t$ to $t+1$ is not 1 .

3. Having established that public capital will only be rented, we now look for the amount that households will decide to rent. Since we assumed that the rental market is competitive, households will take as given the price (34). With this arrangement, there is now no difference between $G$ and the services from $\Gamma$ : both are nondurable and purchased period by period, both are valued equally by all generations alive, and all generations share equally the costs for both. The efficiency result that we established for public consumption thus trivially extends to public capital: households will rent services from public capital up to the point at which

$$
v_{\Gamma}\left(G_{t}, \Gamma_{t}\right)=q_{t}^{\Gamma}-\beta E_{t}\left[\left(1-\delta_{t+1}^{\Gamma}\right) q_{t+1}^{\Gamma}\right]
$$

QED.

\section{B Details of Calibration}

\section{B.1 Demographic Structure}

1. U.S. now.

We use the death rate by age in 2000, from the National Center for Health statistics. For the age structure we use data from the 2000 U.S. Census. We abstract from out-migration from the U.S., which is small. ${ }^{46}$ However, the age structure reflects the effects of nontrivial immigration. It is very straightforward to adapt the model for the possibility of people being "born" at an age $s>0$. We truncate the distribution at age 90, assuming that a 90-year old person dies for sure; we also do not consider people below 18 years of age, so a

\footnotetext{
${ }^{46}$ We tried including it, with little change.
} 
person is "born" when (s)he reaches age 18 or (s)he immigrates. Finally, population growth is taken from the 10-year growth from the 1990 to the 2000 Census, at an annualized rate.

2. U.S. $1880 \mathrm{~s}$.

Mortality data come from Haines [12]. The data are aggregated in 5-year intervals of age, so we used piecewise linear interpolation. For deaths and the age structure (relevant for voters), we only consider males between 21 and 80. We use data from the West Model. For the population growth (which we assume to be relevant for taxpayers), we use the growth of the total U.S. population from 1880 to 1890, annualized. Results change very little if different choices are made regarding the inclusion/exclusion of one sex from the calibration.

3. Illinois now.

For the probability of death, we use the same as the U.S. 2000 example. The probability of death is swamped by the effect of out-migration, so any difference between Illinois and the rest of the U.S. would be quantitatively insignificant for the results. For out-migration, the U.S. Census reports the number of people that left Illinois between 1995 and 2000, by age. We use this to construct an annual probability of out-migration by dividing the number of migrants by 5 . We are implicitly assuming that out-migration is permanent, i.e., a person that leaves Illinois will never return to be an Illinois resident. This is clearly an unrealistic assumption, but we expect the bias introduced by it to be quantitatively small.

\section{B.2 Parameter Choices for Welfare Computations}

We assume that $v(G, \Gamma)=\xi \frac{G^{1-\sigma}}{1-\sigma}+\eta \frac{\Gamma^{1-\sigma}}{1-\sigma}$.

To pin down $\sigma$, we need a measure of the price elasticity of the demand for public goods.

DelRossi and Inman [9] survey related studies, quoting estimates between 0.17 and 5. We choose a unit elasticity and set $\sigma=1$ (log preferences).

To calibrate $\xi$ and $\eta$ for the federal government, we match the fraction of government consumption expenditures to GDP and government gross investment to GDP from NIPA data, which are approximately $6 \%$ and $1 \%$ respectively. For Illinois, we match the ratio of the operat- 
ing budget appropriations to GDP and of capital budget appropriations to GDP (source: BEA for GDP, State of Illinois for spending); these numbers are approximately $7 \%$ and $2 \%$. We do not consider the U.S. in 1880, as the scope of the federal government was extremely limited back then. $^{47}$

We assume that the economy is in steady state, and normalize GDP to $1 .{ }^{48}$ To infer the stock of public capital from the flow of gross investment, we take the depreciation rate to be $6 \%$ (our higher choice, which does not correspond to infrastructure only). We assume that Illinois is following the 1800 s rule, and fix $\xi$ and $\eta$ to match the appropriate ratios under this assumption. Since the federal government is not mandated to follow any constitutional rule in linking taxes and spending, it is less obvious what to assume. Fortunately, the results for the federal government are less sensitive to the specific value chosen: as the wedges in table 2 imply, even drastic changes in the degree of debt financing have only a moderate impact on government spending. We thus assume that the federal government follows a practice that requires, at the margin, an extra dollar in current revenues for each extra dollar in spending of either type; this rule is equivalent to a balanced budget, or to the $3 \%$ deficit/GDP limit of the European stability pact, or to any deficit ceiling which is not conditional on spending.

The implied values for $\xi$ are approximately .078 for the federal government and .093 for Illinois; the implied values for $\eta$ are approximately .02 at the federal level and .036 for Illinois.

\section{Robustness Checks}

The results obtained above rely on the strong assumption of quasilinear preferences. In this section, we study whether they are likely to be robust to alternative specifications of preferences. Unfortunately, when preferences are not quasilinear, a Markov equilibrium will typically depend on the entire distribution of wealth across the living cohorts; computing equilibria with both

\footnotetext{
${ }^{47}$ For the 19th century, we chose to analyze the United States because very good mortality data by age were readily available to us. However, that experiment is mainly designed to inform us about the likely gains for other countries in which national governments played a more prominent role.

${ }^{48}$ Note that, in a growing economy, $\xi$ and $\eta$ should grow at the GDP rate to have balanced growth.
} 
endogenous policy and long-lived overlapping generations is thus infeasible. We will instead study economies in which overlapping generations live for (at most) two periods. We will compare the results for quasilinear preferences and for a more-standard log choice, and will argue that they are quite similar. This makes us optimistic that the results would also be similar in the case of long-lived overlapping generations.

The choice of overlapping generations of two period lived people is useful computationally, but it is also interesting because it stacks the odds against us. To see this, consider the first-order condition that determines public investment in the quasilinear case:

$$
v_{\Gamma}(G, \Gamma)=\operatorname{median}\left(Q_{s}\right)
$$

where $Q_{s}$ in $(23)$ is computed assuming that any additional investment undertaken today is reversed in the subsequent period. If the current median voter stayed in power for the subsequent period as well, the same first-order condition would hold, even without quasilinearity: the envelope condition would imply that, at the margin, the household would be indifferent whether the current additional investment is fully undone next period, or whether some of it is passed on. The presence of conflict generates two departures from this first-order condition: first, the envelope condition no longer holds, since the identity of the median voter changes from one period to the next; second, the median has to be taken over the $Q_{s}$ computed according to the equilibrium process for taxes, so the identity of the median voter might change depending on the speed with which any additional investment is reversed in the subsequent periods. However, both of these factors play a limited role in the quantitative results of the previous section. Most people currently alive (up to age 55 or so) face a fairly flat probability of death for a long time; as a consequence, the choice of next period's median voter is very close to the optimal choice of the current median voter, and even a change in the identity of the median voter is unlikely to cause drastic changes in policy. By contrast, with overlapping generations living for two periods, the conflict between the current median voter (which we will take to be the young, assuming population growth) and the future median voter is extreme, since their survival profiles are radically different.

In the computations below, we compare the outcomes of quasilinear preferences with the 
political outcome when households have preferences given by

$$
\begin{array}{r}
\log c_{0, s}+\log \left(1-l_{0, s}\right)+\xi \log \left(G_{s}\right)+\eta \log \left(\Gamma_{s}\right)+ \\
\beta \theta_{0}\left[\log c_{1, s+1}+\log \left(1-l_{1, s+1}\right)+\xi \log \left(G_{s+1}\right)+\eta \log \left(\Gamma_{s+1}\right)\right]
\end{array}
$$

To simplify the analysis, we assume no uncertainty. We take factor prices as given. We will mainly comment results at the steady state, but similar numbers occur along transition paths.

We construct a sequence of numerical examples. Even though we occasionally chose some parameter values to match data, these are meant purely to illustrate the extent to which quasilinear preferences and log preferences yield similar results.

In example 1, we set one period to be 30 years; this gives households a reasonable life span, but it implies an unreasonably long lag between one policy session and the next. We thus choose the following parameter values:

- $\theta_{0}=1$ : the young survive for sure 1 more period, leading to maximal conflict between the two generations alive;

- $n=1$ : population doubles from one period to the next;

- $r=5$ and $\delta^{k}=.84$ : this corresponds to a yearly depreciation of about $6 \%$ and a net rate of return of capital of $5.62 \%$ per year;

- $\beta=\frac{1}{1+r-\delta^{k}}$ : this implies that the individual consumption profile is flat;

- $\alpha=0.2$ : this implies a half-life of debt of about 3 periods (93 years);

- $\delta^{\Gamma}=0.6$, about $1.7 \%$ per year;

- $w=10$

- $\eta=0.02, \xi=0.133$; this implies that, in the steady state of the golden rule, public investment/GDP is $2 \%$ and public consumption/GDP is $7 \%$.

- Throughout the example, the government is not allowed to issue debt to pay for public consumption; in steady state, this turns out to be efficient, since both generations alive have the same private consumption level and hence the same valuation of the public good. 


\begin{tabular}{|c|c|c|c|}
\hline & $\begin{array}{l}\text { Optimal debt } \\
\text { if starting at golden rule }\end{array}$ & $\begin{array}{c}\text { Steady-state wedge } \\
\text { under balanced budget }\end{array}$ & $\begin{array}{l}\text { Steady-state wedge } \\
\text { under Golden Rule }\end{array}$ \\
\hline Log & $6 \%$ & $3.8 \%$ & $-54 \%$ \\
\hline Linear & $7 \%$ & $4.2 \%$ & $-54.2 \%$ \\
\hline
\end{tabular}

Table 4: Public investment and efficiency in example 1

Table 4 illustrates the results for this case. The first column illustrates the following experiment. We assume that the economy starts from the steady state implied by the political-economic equilibrium that prevails under the golden rule. At time 0 , the fraction $x$ of investment financed through bonds is unexpectedly changed once and for all. We compute the compensating variation that makes each generation indifferent between the original value of $x$ and the new one. Typically, early generations will be hurt by a sudden reduction in $x$, since they will be able to pass on less debt to future generations, while later generations benefit from the lower steady-state level of debt. We aggregate welfare using the interest rate as the discount factor, which would be appropriate if the government could use generation-specific lump-sum transfers for compensation. The optimal amount of debt financing turns out to be quite low in this case: this is not surprising, since most public capital depreciates from one period to the next. More interestingly, log and linear preferences yield almost identical answers.

In the second column, we look at the wedge in the marginal utility of public capital between the efficient provision level and the one prevailing in steady state when the government is not allowed to issue any debt $(x=0)$. In the third, we study the same wedge, but in the steady state when the government follows the golden rule $(x=1)$. Even for these measures of distortion, linear and log preferences yield essentially identical results.

The results of example 1 are driven to a significant extent by the high discount factor and the low durability of public capital. In example 2, we choose numbers closer to a yearly calibration; this implies of course that people in this artificial economy would live only for 2 years.

Parameter values are now: $\theta_{0}=1, n=0.02, \beta=0.96, \delta^{k}=\delta^{\Gamma}=0.06, r=.102$ (such that $\left.\beta=\frac{1}{1+r-\delta^{k}}\right), \alpha=0.045$, and $\eta, \xi$, and $w$ at the same values of the first example. 


\begin{tabular}{|c|c|c|c|}
\hline & $\begin{array}{l}\text { Optimal debt } \\
\text { if starting at golden rule }\end{array}$ & $\begin{array}{l}\text { Steady-state wedge } \\
\text { under balanced budget }\end{array}$ & $\begin{array}{l}\text { Steady-state wedge } \\
\text { under Golden Rule }\end{array}$ \\
\hline Log & $66 \%$ & $59 \%$ & $-16 \%$ \\
\hline Linear & $53 \%$ & $18 \%$ & $-16 \%$ \\
\hline
\end{tabular}

Table 5: Public investment and efficiency in example 2

For this example, the difference between log and linear preferences is more significant. However, this difference almost vanishes if we reduce the probability of survival from young to old age to $\theta_{0}=0.4$, as shown in table 6 . Since $\theta_{0}=0.4$ still implies a high degree of conflict across generations, we view this result as very encouraging for the accuracy of the predictions contained in section 4.

\begin{tabular}{|c|c|c|c|}
\hline & Optimal debt & Steady-state wedge & Steady-state wedge \\
\hline & if starting at golden rule & under balanced budget & under Golden Rule \\
\hline $\log$ & $89 \%$ & $564 \%$ & $-66 \%$ \\
\hline Linear & $89 \%$ & $562 \%$ & $-66 \%$ \\
\hline
\end{tabular}

Table 6: Public investment and efficiency in example 2, with $\theta_{0}=0.4$

Finally, to assess the impact of wealth effects, we change the interest rate $r$ to $22.7 \%$ for the $\log$ economy only, so that, in the steady state, consumption of the old is $12 \%$ higher than that of the young. ${ }^{49}$ The approximation remains acceptable, except for distortion levels that are very far from anything that we considered in section (4).

The presence of a wealth effect implies that a balanced-budget restriction will no longer lead to efficiency in public consumption; since the young are relatively poorer, they will choose a lower level of $G$ than optimality would dictate. Table 8 explores a potential role for letting the government issue debt as a way of restoring efficiency. While allowing a tiny fraction of debt financing improves welfare, the results suggest again that the difference between linear and log

\footnotetext{
${ }^{49}$ For the linear economy, the consumption profile is indeterminate, and an increase in $r$ with no change in $\beta$ would lead to unbounded solutions.
} 


\begin{tabular}{|c|c|c|c|}
\hline & $\begin{array}{l}\text { Optimal debt } \\
\text { if starting at golden rule }\end{array}$ & $\begin{array}{l}\text { Steady-state wedge } \\
\text { under balanced budget }\end{array}$ & $\begin{array}{l}\text { Steady-state wedge } \\
\text { under Golden Rule }\end{array}$ \\
\hline Log & $81 \%$ & $263 \%$ & $-62 \%$ \\
\hline Linear & $89 \%$ & $562 \%$ & $-66 \%$ \\
\hline
\end{tabular}

Table 7: Public investment and efficiency in example 2, with $\theta_{0}=0.4$ and an increasing consumption profile

\begin{tabular}{|c|c|c|}
\hline & $\begin{array}{l}\text { Optimal debt } \\
\text { if starting at golden rule }\end{array}$ & $\begin{array}{l}\text { Steady-state wedge } \\
\text { under Golden Rule }\end{array}$ \\
\hline $\log$ & $6 \%$ & $3 \%$ \\
\hline Linear & $0 \%$ & $0 \%$ \\
\hline
\end{tabular}

Table 8: Public consumption and efficiency in example 2, with $\theta_{0}=0.4$ and an increasing consumption profile

preferences is small; the main implication that spending in nondurable public goods should not be financed through debt is upheld.

\section{References}

[1] Alberto Alesina and Guido Tabellini. A Positive Theory of Fiscal Deficits and Government Debt. Review of Economic Studies, 57(3):403-414, 1990.

[2] Marina Azzimonti Renzo. On the Dynamic Inefficiency of Governments. Mimeo, University of Rochester, 2004.

[3] Olivier J. Blanchard. Debt, Deficits and Finite Horizons. Journal of Political Economy, 93(2):223-247, 1985. 
[4] Henning Bohn and Robert P. Inman. Balanced-Budget Rules and Public Deficits: Evidence from the U.S. States. Carnegie-Rochester Conference Series on Public Policy, 45:13-76, 1996.

[5] E. Cary Brown. Episodes in the Public Debt History of the United States. In Rudiger Dornbusch and Mario Draghi, editors, Public Debt Management: Theory and History, pages 229-254. Cambridge University Press, 1990.

[6] Willem H. Buiter. Ten Commandments for a Fiscal Rule in the E(M)U. Oxford Review of Economic Policy, 19(1):84-99, 2003.

[7] V. V. Chari and Patrick J. Kehoe. Sustainable Plans. Journal of Political Economy, 98(4):783-801, 1990.

[8] V. V. Chari and Preston J. Miller. Playing by the Rules: A Proposal for Federal Budget Reform. In Preston J. Miller, editor, The Rational Expectations Revolution: Readings from the Front Line, pages 169-191. MIT Press, 1994.

[9] Alison F. DelRossi and Robert P. Inman. Changing the Price of Pork: the Impact of Local Cost Sharing on Legislators' Demands for Distributive Public Goods. Journal of Public Economics, 71(2):247-273, 1999.

[10] Jonah B. Gelbach. Migration, the Life Cycle, and State Benefits: How Low Is the Bottom? Journal of Political Economy, 112(5):1091-1130, 2004.

[11] Edward L. Glaeser. The Incentive Effects of Property Taxes on Local Governments. Public Choice, 89(1-2):93-111, 1996.

[12] Michael R. Haines. Estimated Life Tables for the United States, 1850-1900. NBER Historical Paper, 59, 1994.

[13] Lars Peter Hansen, William T. Roberds, and Thomas J. Sargent. Time Series Implications of Present Value Budget Balance and of Martingale Models of Consumption and Taxes. In Rational Expectations Econometrics, pages 121-161. Westview Press, 1991. 
[14] Kevin X.D. Huang and Jan Werner. Implementing Arrow-Debreu Equilibria by Trading Infinitely-Lived Securities. Economic Theory, 24(3):603-622, 2004.

[15] John Maynard Keynes. Indian Currency and Finance. Macmillan and Co, Ltd, 1913.

[16] Bruce D. Meyer. Do the Poor Move to Receive Higher Welfare Benefits? Joint Center for Poverty Research Working Paper, 58, 2000. Northwestern University/ University of Chicago.

[17] Leo Pasvolsky. Economic Nationalism of the Danubian States. The Macmillan Company, 1928.

[18] Ben D. Peletier, Robert A.J. Dur, and Otto H. Swank. Voting on the Budget Deficit: Comment. American Economic Review, 89(5):1377-1381, 1999.

[19] Torsten Persson and Lars E. O. Svensson. Why a Stubborn Conservative would Run a Deficit: Policy with Time-Inconsistent Preferences. Quarterly Journal of Economics, 104(2):325-345, 1989.

[20] James M. Poterba. State Responses to Fiscal Crises: The Effects of Budgetary Institutions and Politics. Journal of Political Economy, 102(4):799-821, 1994.

[21] James M. Poterba. Capital Budgets, Borrowing Rules, and State Capital Spending. Journal of Public Economics, 56(2):165-187, 1995.

[22] James M. Poterba. Do Budget Rules Work? In Alan J. Auerbach, editor, Fiscal policy: Lessons from economic research., pages 53-86. MIT Press, 1997.

[23] James M. Poterba and Kim S. Rueben. Fiscal News, State Budget Rules, and Tax-Exempt Bond Yields. Journal of Urban Economics, 50(3):537-562, 2001.

[24] Antonio Rangel. How to Protect Future Generations Using Tax Base Restrictions. American Economic Review, 95(1):314-346, 2005.

[25] Kenneth Rogoff. Equilibrium Political Budget Cycles. American Economic Review, 80(1):21-36, 1990. 
[26] Kenneth Rogoff and Anne Sibert. Elections and Macroeconomic Policy Cycles. Review of Economic Studies, 55(1):1-16, 1988.

[27] Paul Rothstein. Order Restricted Preferences and Majority Rule. Social Choice and Welfare, $7(4): 331-342,1990$.

[28] Paul Rothstein. Representative Voter Theorems. Public Choice, 72(2-3):193-212, 1991.

[29] Christian Schultz and Tomas Sjöström. Local Public Goods, Debt and Migration. Journal of Public Economics, 80(2):313-337, 2001.

[30] Horace Secrist. An economic analysis of the constitutional restrictions upon public indebtedness in the United States. Bulletin of the University of Wisconsin. Economics and political science series, 8(1), 1914.

[31] Robert Skidelsky. John Maynard Keynes: Fighting for Britain, 1937-1946. MacMillan Pub. Ltd., 2001.

[32] Paul Studensky. Public Borrowing. National Municipal League, 1930.

[33] Guido Tabellini and Alberto Alesina. Voting on the Budget Deficit. American Economic Review, 80(1):37-49, 1990.

[34] John Joseph Wallis. Constitutions, Corporations, and Corruption: American States and Constitutional Change, 1842 to 1852. Journal of Economic History, 65(1):211-256, 2005.

[35] John Joseph Wallis and Barry Weingast. Equilibrium Impotence: Why the States and Not the American National Government Financed Infrastructure Investment in the AnteBellum Era. NBER Working Paper, 11397, 2005. 